\title{
INFLUENCE OF METAL HALIDE PEROVSKITE MODIFICATIONS ON STRUCTURE AND FUNCTIONALITY
}

by

Erin Service

\begin{abstract}
A thesis
submitted to the Victoria University of Wellington in fulfilment of the requirements for the degree of Master of Science
\end{abstract}

Victoria University of Wellington 2017 



\section{Abstract}

Metal halide perovskites $\left(\mathrm{ABX}_{3}\right)$ represent an important class of materials with respect to optoelectronic applications such as photovoltaic and light-emitting devices. In this thesis, modification of these materials was explored through metal substitutions, halide substitutions and also nanocrystal synthesis. The ability for these modifications to take place was analyzed, and related to the effects on structural and optoelectronic properties.

Heterovalent metal substitutions were explored through the substitution of $\mathrm{Bi}^{3+}$ into methylammonium lead iodide $\left(\mathrm{MAPbI}_{3}\right)$. It was found that a two phase material composed of $\mathrm{MAPbI}_{3}$ and $\mathrm{MA}_{3} \mathrm{Bi}_{2} \mathrm{I}_{9}$ forms during these substitutions. This resulted in changes to electron-hole generation in the thin films and separation in photovoltaic devices, as observed through optical absorption and current-voltage measurements. Substitutions of $\mathrm{Bi}^{3+}$ and $\mathrm{Tl}^{+}$were also carried out at dopant concentrations of $0.1-1 \%$. Although the bulk crystal structure was maintained here, the power conversion efficiencies of devices decreased, with a bigger effect measured for $\mathrm{Bi}^{3+}$ doping. The ability for halide ions in $\mathrm{MAPbBr}_{3}$ to be substituted with the thiocyanate ion $(\mathrm{SCN})^{-}$was investigated and compared to previous reports concerning $\mathrm{MAPbI}_{3}$. From the studies conducted here, it is unlikely that the $(\mathrm{SCN})^{-}$ion becomes incorporated into the perovskite crystal lattice. This appeared to be primarily due to the reactivity of $\mathrm{MA}^{+}$ion with $(\mathrm{SCN})^{-}$. Finally, $\mathrm{Cs}_{3} \mathrm{Bi}_{2} \mathrm{I}_{9}$ nanocrystals were synthesized via the hot injection method. This was supported through XRD, TEM and EDS measurements, where the crystals were found to display hexagonal symmetry. Subsequent experiments on the mixed halide nanocrystals $(\mathrm{I} / \mathrm{Br}$ ) revealed the sensitive nature of this synthesis to oxygen contamination. 


\section{Acknowledgement}

I would to take this opportunity to thank the many people who have provided support throughout this past year at the Victoria University of Wellington. Thank you to my supervisor Dr. Jonathan Halpert, for the guidance and many discussions concerning this project. I have gained knowledge and skills that will help me to move forward in my career.

Thank you to my fellow lab mates, Mark, Parth, Matt and Michael. I appreciate the time taken by everyone to help me in numberous ways around the lab, including instrument training, methodology and theoretical problems.

Thank you as well to David Flynn, for training, support, and free coffee in the electron microscope suite. Also to Dr. Natalie Plank, for access to the cleanroom facility which aided in device fabrication.

I have many people to thank for providing personal support throughout the past year. To my family, for supporting my move to New Zealand and providing advice throughout the year. Also to my friends, now in New Zealand, Canada, or elsewhere, for the laughs, roadtrips, and good conversation.

Resources and funding for this project were provided by the Royal Society of New Zealand Marsden Fund and Rutherford Fund, the Victoria University of Wellington and the MacDiarmid Institute for Advanced Materials and Nanotechnology. 


\section{Contents}

1 Background and Theory 1

1.1 Semiconductor Materials . . . . . . . . . . . . . . . . . . 1

1.1.1 Band Theory of Solids . . . . . . . . . . . . . . . 1

1.1.2 Electrical Conduction in Semiconductors . . . . . . . . . 2

1.1.3 Doping in Semiconductors . . . . . . . . . . . . . . . 4

1.1.4 Heterojunction Solar Cells . . . . . . . . . . . . . . . . . 6

1.2 Metal Halide Perovskites . . . . . . . . . . . . . . . . 7

1.2.1 The Perovskite Unit Cell . . . . . . . . . . . . . . 7

1.2.2 Methylammonium Lead Iodide Materials and Properties . . 9

1.2.3 Methylammonium Lead Iodide in Photovoltaics . . . . . . . 10

1.3 Substitution in Metal Halide Perovskites . . . . . . . . . . . . . 11

1.3.1 Halide Substitution . . . . . . . . . . . . . . . . . 11

1.3.2 Cation Substitution . . . . . . . . . . . . . . 12

1.3.3 Metal Substitution . . . . . . . . . . . . . . 13

1.4 Nanocrystals of Metal Halide Perovskite Materials . . . . . . . . . . 14

1.4.1 Synthesis and Properties of Nanocrystals . . . . . . . . . 14

1.4.2 Lead Halide Perovskite Nanocrystals . . . . . . . . . . . . . 15

2 Methods 18

2.1 Synthesis Procedures . . . . . . . . . . . . . . . . . . . 18

2.1.1 Thin Film Deposition . . . . . . . . . . . . . . . . . 18

2.1.2 Hot Injection Nanocrystal Synthesis . . . . . . . . . . . . . . 19

2.2 Characterization Procedures . . . . . . . . . . . . . . . . . 19

2.2.1 Ultraviolet-Visible Absorbance Spectroscopy . . . . . . . . . 19

2.2.2 Photoluminescence Spectroscopy _ . . . . . . . . . . . 20

2.2 .3 X-ray Diffraction . . . . . . . . . . . . . 20 
2.2.4 Scanning Electron Microscopy . . . . . . . . . . . . . 21

2.2.5 Transmission Electron Microscopy . . . . . . . . . . . . . . 23

2.2.6 Solar Cell Efficiency _. . . . . . . . . . . . . . . . 23

3 Metal Ion Substitutions in Lead Halide Perovskites 26

3.1 Mixed Bismuth and Lead Halide Perovskite Thin Films . . . . . . . 26

3.1.1 Motivation . . . . . . . . . . . . . 26

3.1 .2 Methods . . . . . . . . . . . . . . . . 27

3.1.3 Results and Discussion . . . . . . . . . . . . . . . . . 29

3.2 Bismuth and Thallium Doping in $\mathrm{MAPbI}_{3} \ldots \ldots$. . . . . . . . . 33

3.2.1 Motivation . . . . . . . . . . . . . . . 33

3.2.2 Methods . . . . . . . . . . . . . . . . 34

3.2.3 Results and Discussion . . . . . . . . . . . . . . . 35

3.3 Conclusions . . . . . . . . . . . . . . . . . . . . . 39

4 Pseudo-Halide Substitution in Metal Halide Perovskites 41

4.1 Thiocyanate Substitution in $\mathrm{MAPbBr}_{3} \ldots \ldots \ldots$. . . . . . . . 41

4.1.1 Motivation .................... 41

4.1 .2 Method .................... . . 42

4.1.3 Results and Discussion . . . . . . . . . . . . . . . . 43

4.2 Conclusions . . . . . . . . . . . . . . . . . . . . . . . . . . 48

5 Properties of $\mathrm{Cs}_{3} \mathrm{Bi}_{2} \mathrm{X}_{9}$ Nanocrystals $\quad 51$

$5.1 \quad \mathrm{Cs}_{3} \mathrm{Bi}_{2} \mathrm{I}_{9}$ Nanocrystals . . . . . . . . . . . . . . . . 51

5.1 Motivation .................... 51

5.1 .2 Methods ....................... 52

5.1 .3 Results and Discussion . . . . . . . . . . . . 53

5.2 Conclusions . . . . . . . . . . . . . . . . . . . . 60 


\section{List of Figures}

1.1 Band characteristics of solid state materials . . . . . . . . . . 1

1.2 Photoconductivity in semi-conductors . . . . . . . . . . . . . 3

1.3 Energy levels of n- and p-type extrinsic semiconductors . . . . . . 5

1.4 Energy levels in a heterojunction solar cell . . . . . . . . . . . . . . 7

1.5 The perovskite unit cell . . . . . . . . . . . . . . . . 8

2.1 Spin coating thin films . . . . . . . . . . . . . . . . . . . 18

2.2 X-ray diffraction . . . . . . . . . . . . . . . . 21

2.3 SEM Analysis . . . . . . . . . . . . . . . . . . . . 22

2.4 Current Density-Voltage characteristics of a photovoltaic device . . 24

3.1 XRD and SEM: Bismuth Substitutions in $\mathrm{MAPbI}_{3} \ldots \ldots . \ldots$

3.2 UV-Vis and Tauc Analysis: Bismuth Substitutions in $\mathrm{MAPbI}_{3}$. . . 31

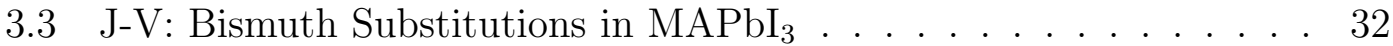

3.4 XRD: $\mathrm{Bi}^{3+}$ and $\mathrm{Tl}^{+}$doping in $\mathrm{MAPbI}_{3} \ldots \ldots \ldots . \ldots . . \ldots 35$

3.5 UV-Vis and Tauc Analysis: $\mathrm{Bi}^{3+}$ and $\mathrm{Tl}^{+}$doping in $\mathrm{MAPbI}_{3} \ldots$. . 36

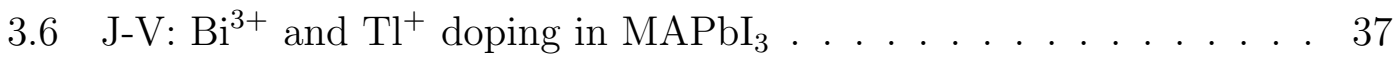

3.7 Box-Whisker: $\mathrm{Bi}^{3+}$ and $\mathrm{Tl}^{+}$doping in $\mathrm{MAPbI}_{3} \ldots \ldots . . . . . .38$

4.1 XRD: $\mathrm{SCN}^{-}$substitution in $\mathrm{MAPbBr}_{3} \ldots \ldots \ldots . \ldots . \ldots . . \ldots 43$

4.2 SEM: $\mathrm{SCN}^{-}$substitution in $\mathrm{MAPbBr}_{3} \ldots \ldots \ldots \ldots$

$4.3 \mathrm{UV}-\mathrm{V}$ is and $\mathrm{PL}: \mathrm{SCN}^{-}$substitution in $\mathrm{MAPbBr}_{3} \ldots \ldots . . . . .47$

5.1 XRD: $\mathrm{Cs}_{3} \mathrm{Bi}_{2} \mathrm{I}_{9}$ nanocrystals . . . . . . . . . . . . . 53

5.2 UV-Vis and Tauc Analysis: $\mathrm{Cs}_{3} \mathrm{Bi}_{2} \mathrm{I}_{9}$ nanocrystals . . . . . . . . . 54

5.3 TEM: $\mathrm{Cs}_{3} \mathrm{Bi}_{2} \mathrm{I}_{9}$ nanocrystals . . . . . . . . . . . . . . . . . 55

5.4 XRD: Mixed halide nanocrystal synthesis . . . . . . . . . . . . . . 56

5.5 UV-Vis and Tauc Analysis: Mixed halide nanocrystal synthesis . . . 58

5.6 TEM: Mixed halide nanocrystal synthesis . . . . . . . . . . . . . . . 59

5.7 STEM: Mixed halide nanocrystal synthesis . . . . . . . . . . . . . 59 


\section{Background and Theory}

\subsection{Semiconductor Materials}

\subsubsection{Band Theory of Solids}

The band theory of solids describes the interaction of atomic orbitals as discrete atoms come together to form a bulk solid. ${ }^{1}$ As these atoms move close to each other, the overlap of the orbitals causes a splitting of the energy levels. ${ }^{1}$ These levels remain discrete for small numbers of interacting atoms, however as more orbitals are added to the material, the spacing between the levels decrease. ${ }^{1}$ Effectively, these atomic levels become a continuum of states over a given energy range, called a band, in which electrons reside. ${ }^{1}$ In a solid, there may be many bands separated by forbidden energy gaps, in which the electrons do not exist. ${ }^{1}$ Metals, semi-conductors and insulators are characterized through conduction properties, which are determined by the occupancy of two bands, and the magnitude of the energy gap between them. ${ }^{1}$ The valence band is defined as the band at the highest energy that contains electrons at $0 \mathrm{~K} .{ }^{1}$ The conduction band is the next highest band in energy, and is empty at $0 \mathrm{~K}$ for all materials. ${ }^{1}$ In metals, the conduction

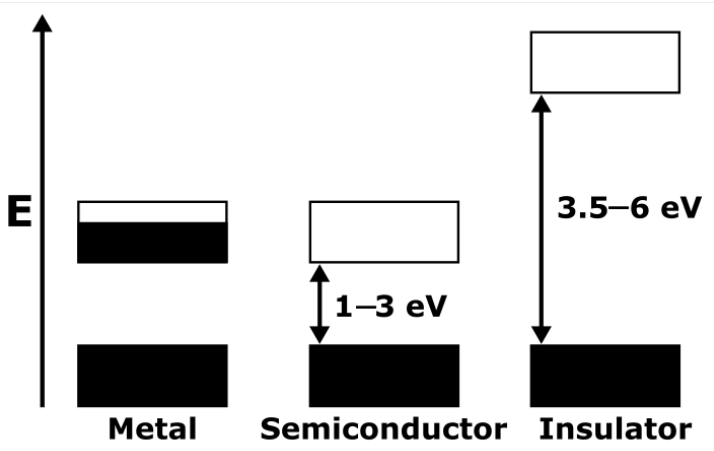

Figure 1.1: Relative energy level spacing of allowed bands in metals, semiconductors and insulators, as labelled. Shading indicates electron population in a given band at $0 \mathrm{~K}$. 
band is partially full, and electrons move freely between empty states within the band. ${ }^{1}$ Alternatively, semiconductors and insulators have a full valence band at $0 \mathrm{~K}$, which prevents current from flowing in the absence of additional external energy. ${ }^{1}$ As the bandgap of semiconductors is between 1.0 and $3.0 \mathrm{eV}$, thermal or radiative energy incident on the material may be sufficient to promote electrons in the valence band to the conduction band. ${ }^{1}$ Upon this promotion, vacancies are created in the valence band, which act as additional charge carriers, called holes. ${ }^{1}$ Insulators however, have bandgaps greater than $3.5 \mathrm{eV}$, which prevents electron promotion through thermal or radiative sources. ${ }^{1}$ A representation of the valence and conduction bands of metals, semiconductors and insulators is shown in Fig. 1.1, where shading indicates electron population in a given band.

\subsubsection{Electrical Conduction in Semiconductors}

As discussed, the promotion of electrons to the valence band of a semiconductor leaves behind an equal number of holes, both of which can carry charge throughout the material. ${ }^{1}$ Upon application of an external electric field, $\vec{E}$, the movement of holes and electrons create electric current. ${ }^{1}$ The motion of these charge carriers throughout the crystal is dependent on the effective mass $\left(m^{*}\right)$ of each particle, which takes into account all internal forces within the material and allows them to be treated as Newtonian particles. ${ }^{1}$ The effective mass is also a parameter determining the density of states in the valence $\left(g_{v}(E)\right)$ and conduction $\left(g_{c}(E)\right)$ bands,

$$
\begin{aligned}
& g_{v}(E)=\frac{4 \pi\left(2 m_{p}^{*}\right)^{3 / 2}}{h^{3}} \sqrt{E_{v}-E} \\
& g_{c}(E)=\frac{4 \pi\left(2 m_{n}^{*}\right)^{3 / 2}}{h^{3}} \sqrt{E-E_{c}}
\end{aligned}
$$

where $m_{p}^{*}$ and $m_{n}^{*}$ are the effective masses of the hole and electron, respectively, and $E_{v}$ and $E_{c}$ are the energies of the top of the valence band and bottom of the 
conduction band, respectively. ${ }^{1}$ The ratio of filled to available states, at a given energy $(E)$ and temperature $(T)$ is described by the Fermi-Dirac distribution,

$$
f_{F}(E)=\frac{1}{1+\exp \left(\frac{E-E_{F}}{k T}\right)}
$$

where $E_{F}$ is the Fermi energy, and $k$ is the Boltzmann constant. ${ }^{1}$ At $0 \mathrm{~K}$, this distribution is unity at energies below $E_{F}$ and zero above $E_{F} \cdot{ }^{1}$ It follows that the Fermi energy lies within the bandgap of semiconductor materials. ${ }^{1}$ Further, if the effective masses of holes and electrons are equal, the Fermi energy lies in the middle of the bandgap,

$$
E_{F i}-E_{\text {midgap }}=\frac{3}{4} k T \ln \left(\frac{m_{p}^{*}}{m_{n}^{*}}\right)
$$

which is a consequence of the symmetric nature of $g_{c}$ and $g_{v}$ when $m_{n}^{*}=m_{p}^{*}$.

Excitation of electrons to the conduction band may also be achieved optically, as many semiconductors have a bandgap corresponding to an energy within the visible spectrum. ${ }^{1}$ Fig. 1.2 illustrates this process, where electromagnetic radiation with energy, $h \nu$, equal to $E_{g}$ creates an electron-hole pair. In practical applications, the radiation interacting with a semiconductor will have a range of energies, most of

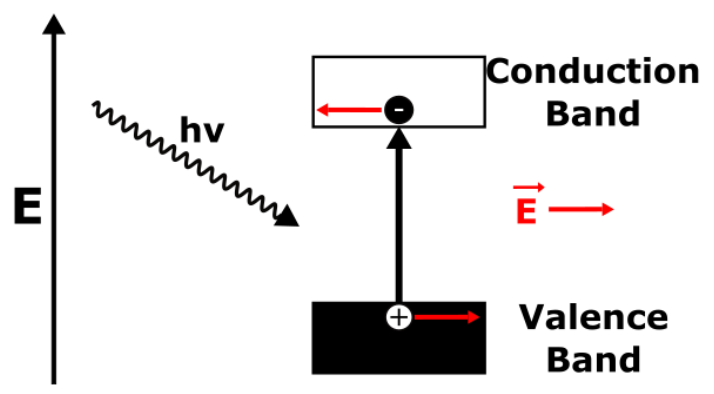

Figure 1.2: Creation of an electron-hole pair upon optical irradiation of energy, $E=E_{g}$, followed by electric conduction due to an external electric field, $\vec{E}$. 
which do not correspond to the bandgap of the material. ${ }^{1}$ Radiation with energy greater than $E_{g}$ continues to create an electron-hole pair within the material, where the excess energy is subsequently dissipated as heat. ${ }^{1}$ For incident radiation that has an energy less than $E_{g}$ however, no electron-hole pair is created. ${ }^{1}$ The ability for semiconductors to absorb photons with specific wavelengths is quantified by the absorption coefficient $(\alpha)$, which is measured in $\mathrm{cm}^{-1} .{ }^{1}$ The intensity of radiation at a defined distance within a semiconductor is an exponential function of $\alpha$,

$$
I_{v}(x)=I_{v 0}(x) e^{-\alpha x}
$$

where $I_{v}(x)$ and $I_{v 0}(x)$ are the intensities of radiation at a distance, $x$, within the material and at the surface of the material, respectively. ${ }^{1}$ Relating the absorption coefficient back to the energy of incident radiation, it follows that $\alpha$ is small for energies smaller than the bandgap, and large for energies greater than or equal to the bandgap. ${ }^{1}$

\subsubsection{Doping in Semiconductors}

The undoped semiconductors described in Sec. 1.1.2 are known as intrinsic semiconductors. ${ }^{1}$ These materials display an increase in conductivity as a result of electron-hole pair generation and therefore necessarily have an equal number of holes and electrons. ${ }^{1}$ Alternatively, an intrinsic semiconductor such as silicon may be doped with impurity atoms to create an extrinsic semiconductor. ${ }^{1}$ The impurity atoms create additional discrete energy levels within the bandgap and alter the distribution of charge carriers in the material, as illustrated in Fig. 1.3. ${ }^{1}$ As an example, silicon may be doped with either boron or phosphorous, which have three and five valence electrons, respectively. ${ }^{1}$ The addition of boron into the silicon lattice results in a vacant bonding site. ${ }^{1}$ This site will have an energy slightly higher 


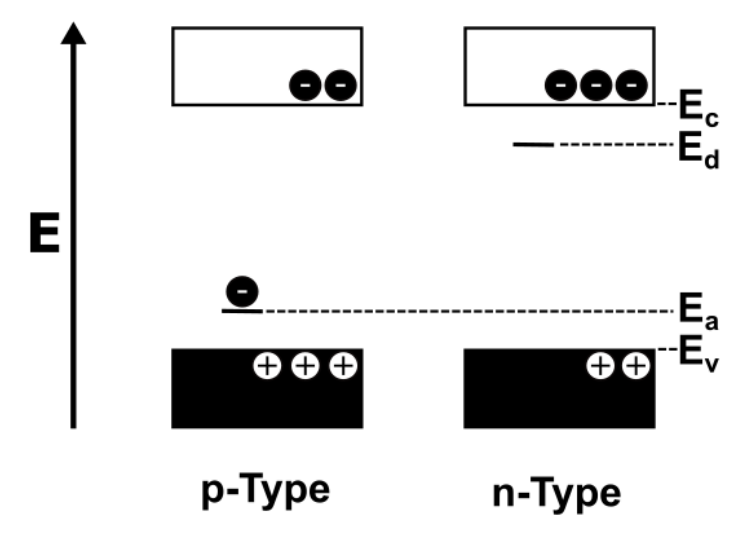

Figure 1.3: Additional discrete energy levels introduced through doping of an intrinsic semiconductor. $E_{a}$ is an acceptor state in a p-type material and $E_{d}$ is a donor state in a n-type material, which creates an excess of holes and electrons, respectively, in the material.

than the valence band, as occupation of this site will cause the dopant to carry a negative charge. ${ }^{1}$ However, at ambient temperatures, this site may easily accept electrons and leave behind a hole in the valence band. ${ }^{1}$ It is therefore termed an acceptor level, with energy, $E_{a}$, and the material is now a p-type semiconductor, due to the creation of positive charges in the valence band. ${ }^{1}$ Alternatively, adding phosphorous as a dopant leaves the fifth electron unbound in the lattice, which can be readily promoted to the conduction band, compared to other covalently bonded atoms. ${ }^{1}$ It therefore initially occupies a donor state just below the conduction band, at energy, $E_{d}{ }^{1}$ These materials are termed n-type, where the $\mathrm{n}$ represents the electron which is now the majority charge carrier. ${ }^{1}$ Doping a semiconductor has significant effects on properties of the material. ${ }^{1}$ The relation of the distribution function to the Fermi energy causes it to shift from the middle of the bandgap. ${ }^{1}$ Additionally, as there are unequal numbers of electrons and holes in extrinsic materials, the drift current $\left(J_{d r f}\right)$ due to an external electric field is now 
dominated by the majority charge carrier,

$$
J_{d r f}=e\left(\mu_{n} n+\mu_{p} p\right) E
$$

where $e$ is the magnitude of the fundamental charge, $\mu_{n}$ and $\mu_{p}$ are the electron and hole mobilities, respectively and $n$ and $p$ are the electron and hole volume densities. ${ }^{1}$ The velocity with which electrons and holes move throughout a material is a function of the external field and the carrier mobility. ${ }^{1}$ The mobility itself is dependent on the number of collisions, or the degree of scattering, occurring for a charge carrier within the lattice. ${ }^{1}$ Whereas lattice scattering occurs within all semiconductors due to atomic vibrations, additional scattering occurs due to ionized impurities at dopant sites in the lattice. ${ }^{1}$

\subsubsection{Heterojunction Solar Cells}

Heterojunction solar cells consist of a semiconducting material sandwiched by two charge collectors which serve to separate photogenerated electron-hole pairs. ${ }^{2}$ Electrons promoted to the conduction band of the semiconductor upon light absorption are transferred to the conduction band of the electron transport layer (ETL). ${ }^{2}$ This ETL is generally a wide bandgap oxide semiconductor that is transparent to the visible spectrum, such as $\mathrm{TiO}_{2} \cdot{ }^{2}$ Holes remaining in the valence band are transferred through the hole transport layer (HTL) to a current collector. ${ }^{2}$ They are then recombined with the electrons, which have since passed through an external circuit to do electrical work. ${ }^{2}$ Through this process, the absorbing material does not undergo a chemical change as optical energy is converted to electrical work. $^{2}$ Separation of electrons and holes is favoured over recombination within the semiconductor if the energy levels of the ETL, semiconductor and HTL are appropriately aligned. ${ }^{3}$ As shown in Fig. 1.4, dissociation of the electron-hole pair occurs 


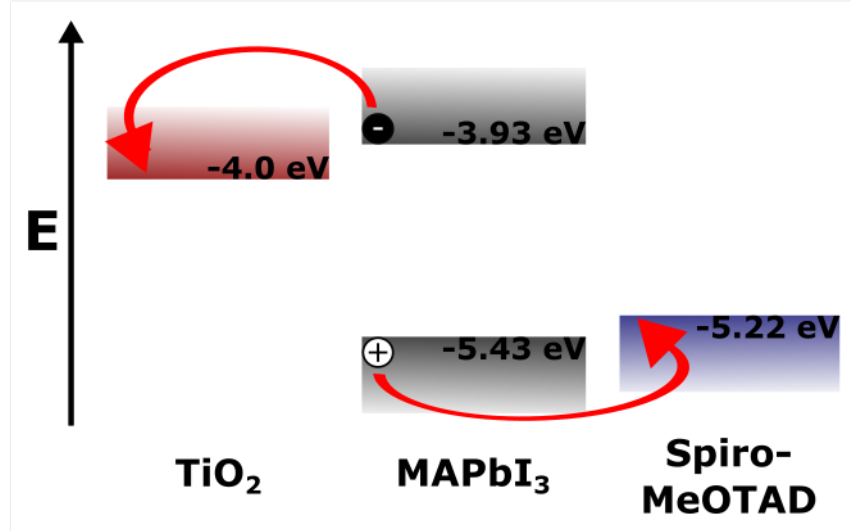

Figure 1.4: The energy levels and charge carrier transport of a heterojunction solar cell, where $\mathrm{TiO}_{2}$ is the ETL, $\mathrm{MAPbI}_{3}$ is the absorbing layer and spiro-MeOTAD is the HTL.

when the conduction band of the ETL is lower in energy than that of the absorbing material. ${ }^{3,4}$ Also, the valence band of the HTL must reside at a higher energy than that of the absorbing material. ${ }^{3}$ Fig. 1.4 shows energy levels of a metal halide perovskite solar cell, discussed in Sec. 1.2.3., where $\mathrm{TiO}_{2}$ is the ETA, methylammonium lead iodide $\left(\mathrm{MAPbI}_{3}\right)$ is the absorbing layer and $2,2^{\prime}, 7,7^{\prime}$-tetrakis- $(\mathrm{N}, \mathrm{N}$ di-p-methoxyphenylamine) 9,9'-spirobifluorene (spiro-MeOTAD) is the HTL. ${ }^{4}$ The bandgap of the absorbing layer must allow absorption over a wide range of visible light for efficient conversion of optical to electric energy. ${ }^{5}$ While a smaller bandgap is able to collect a broader range of solar energy and generate more current, this comes at a cost of decreasing the voltage of the device. ${ }^{5}$

\subsection{Metal Halide Perovskites}

\subsubsection{The Perovskite Unit Cell}

The term perovskite, while first attributed to the mineral calcium titanate $\left(\mathrm{CaTiO}_{3}\right)$, has come to represent a wide range of materials with varying elemental compositions. ${ }^{6}$ The crystal structure consists of repeating $\mathrm{ABX}_{3}$ units, where $\mathrm{A}$ and $\mathrm{B}$ 
are cations, and $\mathrm{X}$ is an anion balancing the charge of the structure. ${ }^{6}$ These unit cells are connected through the corners of octahedral cages created by the anions as shown in Fig. 1.5, where the $a, b$ and $c$ axes may be used to specify lattice parameters. ${ }^{6}$ The B cations reside within octahedral cages, while the A cations fill the 12 coordinate spaces between cages. ${ }^{6}$ The stability and symmetry of this structure is largely determined by the relative size of atoms in the unit cell, and can be quantified through the Goldschmidt tolerance factor,

$$
t=\frac{r_{A}+r_{X}}{\sqrt{2}\left(r_{B}+r_{X}\right)}
$$

where $r_{A}, r_{B}$ and $r_{X}$ represent the ionic radii of the ions within the structure. ${ }^{7}$ For $t=1$, a symmetric, cubic perovskite structure will be stable. If the tolerance factor is slightly greater or less than 1, structural distortions occur to stabilize the perovskite structure. ${ }^{6}$ However if the tolerance factor lies outside the limits of $0.7<t<1.1$, an alternate structure will be preferred. ${ }^{6}$ Traditionally, the tolerance factor is used for inorganic perovskites, where all ions may be approximated as hard spheres. ${ }^{6}$ However, organic cations have also been successfully incorporated into the A site of the unit cell. ${ }^{8,9}$ In an effort to extend the tolerance factor parameter to these organic-inorganic structures, a set of effective radii was assigned

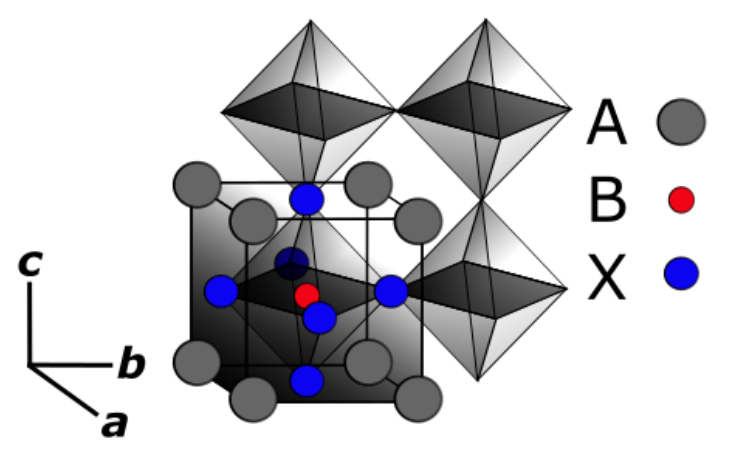

Figure 1.5: The perovskite unit cell. The lattice is constructed of repeating cells, where the octahedral cages are connected through corners, as shown. 
to common organic cations such as methylammonium $\left(\mathrm{MA}^{+}\right)$and formamidinium $\left(\mathrm{FA}^{+}\right)$which had the potential to stabilize the structure. ${ }^{10}$ These values, based on the assumption of free rotation around the center of mass, produced tolerance factors that agree with current experimental data. ${ }^{10}$

\subsubsection{Methylammonium Lead Iodide Materials and Properties}

Methylammonium lead halide perovskites $\left(\mathrm{MAPbX}_{3}, \mathrm{X}=\mathrm{I}, \mathrm{Br}, \mathrm{Cl}\right)$ have become popular in recent years for use in photovoltaics and light-emitting devices. ${ }^{5,11,12}$ As a solution processable semiconductor, devices may be fabricated from this material using low cost methods such as spin coating. ${ }^{12}$ While exploration into these applications has only become popular over the past five years, $\mathrm{MAPbI}_{3}$ and related perovskites are not novel. ${ }^{13,8,14}$ In 1958, the synthesis of $\mathrm{CsPbI}_{3}, \mathrm{CsPbBr}_{3}$, and $\mathrm{CsPbCl}_{3}$ crystals was reported, and these materials were found to display photoconductivity. ${ }^{13}$ An organic cation was first incorporated into the perovskite structure in 1978 with the synthesis of $\mathrm{MAPbI}_{3}, \mathrm{MAPbBr}_{3}$ and $\mathrm{MAPbCl}_{3}$ crystals, however no significant electrical properties were reported at the time. ${ }^{8}$ Today, many optical and electrical properties of $\mathrm{MAPbI}_{3}$ have now been studied and determined. ${ }^{15,16,17,18,19,20,21,22}$ At room temperature, $\mathrm{MAPbI}_{3}$ crystallizes in a tetragonal unit cell where $\mathrm{a}=\mathrm{b}=8.855 \AA$ and $\mathrm{c}=12.659 \AA .{ }^{15,16}$ Above 327.4 $\mathrm{K}$, the unit cell undergoes a change in symmetry to become cubic, whereas below 162.2 K, the unit cell is orthorhombic. ${ }^{15,16}$ With a bandgap of $1.55 \mathrm{eV}$, this material is able to absorb incident light throughout the visible region and up to 800 $\mathrm{nm} .{ }^{17}$ A high absorption coefficient of $1.5 \times 10^{4} \mathrm{~cm}^{-1}$ at $550 \mathrm{~nm}$ reveals that thin layers of this material may be used for efficient optical absorption, adding to the low cost appeal of this material. ${ }^{18}$ Long charge diffusion lengths of $100 \mathrm{~nm}$ were discovered for both holes and electrons, which helped to explain high efficiencies seen in photovoltaic devices fabricated with this material. ${ }^{19,20}$ Additionally, am- 
bipolar transport of charges throughout $\mathrm{MAPbI}_{3}$ was displayed through successful harvesting of incident light using devices lacking either the ETL or HTL. ${ }^{21,22}$

\subsubsection{Methylammonium Lead Iodide in Photovoltaics}

The efficiencies of photovoltaic devices employing lead halide perovskites as the absorbing material have increased steadily over the past 6 years. ${ }^{4,17,21,23,24,25,26}$ The first organic-inorganic perovskite solar cell used this material in the form of nanocrystals within a redox active electrolyte. ${ }^{17}$ Efficiencies of $3.81 \%$ and $3.13 \%$ were reported for devices using $\mathrm{MAPbI}_{3}$ and $\mathrm{MAPbBr}_{3}$, respectively. ${ }^{17}$ In 2012 , two groups replaced the electrolyte with a solid state hole transport material, resulting in a jump in both efficiency and stability for these devices. ${ }^{4,21}$ Kim et al. fabricated a device with $\mathrm{MAPbI}_{3}$ nanocrystals infiltrating the pores of a mesoporous $\mathrm{TiO}_{2}$ scaffold, and layered with spiro-MeOTAD, resulting in an efficiency of $9.7 \% .{ }^{4}$ This was closely followed by a device using $\mathrm{MAPbI}_{2} \mathrm{Cl}$ as the active layer in a very similar architecture, with an efficiency of $7.6 \% .^{21}$ In the same report, the electron transport capabilities of the perovskite were also discovered through replacement of $\mathrm{TiO}_{2}$ with $\mathrm{Al}_{2} \mathrm{O}_{3} \cdot{ }^{21}$ This insulating scaffold forced electrons to be transported through the perovskite itself, if possible, which was confirmed as an efficiency of $10.9 \%$ was observed. ${ }^{21}$ In 2013 , a 2-step solution deposition and a vapor deposition were used for device fabrication. ${ }^{23,24}$ A maximum power conversion efficiency of $15.0 \%$ was obtained by first depositing a solution of $\mathrm{PbI}_{2}$ into the pores of a mesoporous $\mathrm{TiO}_{2}$ layer, and subsequently dipping this film into a solution of methylammonium iodide (MAI). ${ }^{23}$ This efficiency was attributed to high photocurrents of $20 \mathrm{mAcm}^{-2}$, due to an increased concentration of perovskite within the scaffold, compared to previous reports. ${ }^{23}$ Shortly after this report, a $15.4 \%$ cell was fabricated via vapor deposition of the perovskite absorber $\mathrm{MAPbI}_{3-x} \mathrm{Cl}_{x}$ onto a planar $\mathrm{TiO}_{2}$ substrate. ${ }^{24}$ In addition to developing a new deposition technique 
for the halide perovskite, this showed that a mesoporous metal oxide scaffold was not necessary for high efficiency devices. ${ }^{24}$ Compared to a solution processed layer, which resulted in short circuit paths in areas where the material failed to cover the substrate, vapor deposition allowed very uniform films to be obtained. ${ }^{24}$ This also allowed a high degree of control over film thickness, such that it could be tuned to agree with the charge diffusion lengths within the material. ${ }^{24}$ Compositional engineering in 2015 showed that an absorbing layer of $\left(\mathrm{FAPbI}_{3}\right)_{0.85}-\left(\mathrm{MAPbI}_{3}\right)_{0.15}$ could yield a device with a $17.9 \%$ efficiency. ${ }^{25}$ Recently, a $20.4 \%$ efficiency was obtained for a device, where again, the absorbing layer consisted of a perovskite with mixed ions in both the $\mathrm{A}$ and $\mathrm{X}$ site. ${ }^{26}(\mathrm{FA})_{1-x}(\mathrm{MA})_{x} \mathrm{~Pb}\left(\mathrm{I}_{1-x} \mathrm{Br}_{x}\right)_{3}$ was deposited on a mesoporous $\mathrm{TiO}_{2}$ scaffold via a 2 step deposition, such that the first metal halide layer was present as a capping layer on the scaffold, and had a mesoporous structure itself. ${ }^{26}$ These pores provided space for the perovskite lattice to expand during addition of the metal halide salt, and a high surface area for a fast and complete reaction. ${ }^{26}$ This small sampling of device architectures shows the versatility in which a lead halide perovskite may be successfully incorporated into a photovoltaic device.

\subsection{Substitution in Metal Halide Perovskites}

\subsubsection{Halide Substitution}

The ability to form mixed halide materials through ionic substitution is a common feature of perovskites. ${ }^{5,6,27}$ Ions of the same charge and similar ionic radius are likely to be incorporated into the crystal structure without vacancies or defects forming. ${ }^{6}$ In metal halide perovskites, it has been shown that varying the occupancy of the $\mathrm{X}$ site allows for continuous tuning of the physical structure and electronic properties of these materials. ${ }^{28,29,30}$ As iodide was replaced with bromide 
in $\mathrm{MAPbBr}_{x} \mathrm{I}_{3-x}$, a contraction of the perovskite lattice was seen, accompanied by an increase in the room temperature symmetry of the unit cell from tetragonal to cubic. ${ }^{28}$ Optically, this substitution caused the bandgap of the material to increase from $1.58 \mathrm{eV}$ to $2.28 \mathrm{eV}$ for $\mathrm{MAPbI}_{3}$ and $\mathrm{MAPbBr}_{3}$, respectively. ${ }^{28}$ This effect was also observed in related materials such as $\mathrm{FAPbBr}_{x} \mathrm{I}_{3-x}{ }^{29}$ Theoretical bandgap calculations for materials sharing the same A and B site cations supported these observations by reporting a trend between the electronegativity of the halide ion and the bandgap of the material. ${ }^{31}$ Generally, increasing the electronegativity of the halide increased the bandgap of the material. ${ }^{31} \mathrm{~A}$ detailed study focusing on the electronic properties of the tin based halide perovskites reported that contributions to the energy levels surrounding the bandgap consist of inorganic contributions from the $\mathrm{B}$ and $\mathrm{X}$ ions, explaining the large changes in optical properties seen upon chemically altering the octahedra. ${ }^{30}$

\subsubsection{Cation Substitution}

Substitution of the organic cation in these perovskites has also been explored..$^{9,29,30}$ Despite a large number of known monovalent organic cations, the fairly rigid size constraint of this lattice site has restricted most studies to $\mathrm{MA}^{+}$and $\mathrm{FA}^{+} .9,29,30$ Inorganic halide perovskites using $\mathrm{Cs}^{+}$in the A site have also been synthesized. ${ }^{29}$ The contribution of this ion to the total density of states was found to occur in flat regions far from the bandgap, and so chemical modification of this lattice site is not expected to directly influence optical properties of the materials. ${ }^{30}$ Effects of A site substitution were found to be structural, where the lattice may expand, contract, or experience octahedral tilting to accommodate small variations in the radius of the cation. ${ }^{30}$ However, in addition to chemical modification of the inorganic framework, changes in bond lengths and angles between the B and X ions were also found to affect bandgap of the material. ${ }^{30}$ Therefore, structural changes observed 
upon A site substitution indirectly affect the optical properties of the materials. ${ }^{30}$ This has been demonstrated through experimental studies of $\mathrm{MAPbI}_{3}, \mathrm{FAPbI}_{3}$ and $\mathrm{CsPbI}_{3} \cdot{ }^{9,29}$ Room temperature absorbance of these materials showed a decrease in the bandgap upon increasing the effective radii of the cation from $\mathrm{Cs}^{+}$to $\mathrm{MA}^{+}$to $\mathrm{FA}^{+} \cdot 9,29$

\subsubsection{Metal Substitution}

Exploration of alternate $\mathrm{B}$ site cations in $\mathrm{MAPbI}_{3}$ and related materials has been largely motivated by toxicity concerns of the lead ion. ${ }^{27,32,33,34,35}$ It has been suggested that many transition metals have appropriate oxidation states to be incorporated into a perovskite structure, although the corner sharing network of halide octahedra may be compromised due to varying ionic radii. ${ }^{27}$ Tin has been explored in multiple studies as a less toxic substitution for lead in both $\mathrm{MAPbX}_{3}$ and $\mathrm{CsPbX}_{3}$, with favorable optical modifications. ${ }^{32,33,34}$ A device employing $\mathrm{MASnI}_{3-x} \mathrm{Br}_{x}$ obtained an efficiency of $5.73 \%$, with a bandgap of $1.75 \mathrm{eV} .{ }^{32}$ The pure iodide counterpart displayed a smaller bandgap of $1.3 \mathrm{eV} .^{32}$ This was a promising start, although all fabrication and measurement procedures were carried out under nitrogen due to the favourable oxidation of $\mathrm{Sn}^{2+}$ to $\mathrm{Sn}^{4+} .32$ Soon after, a decrease in bandgap was measured as $x$ was increased from 0 to 0.7 within $\mathrm{MASn}_{x} \mathrm{~Pb}_{1-x} \mathrm{I}_{3} \cdot{ }^{33}$ This pushed the wavelength of the absorption edge into the near-infrared, from $800 \mathrm{~nm}$ to 1060 nm for $x=0$ and $x=0.7$, respectively. ${ }^{33}$ Additionally, an increase in ambient stability was observed via absorption measurements for the $x=0.5$ material, compared to the $x=1$ material, which demonstrated that a combination of both lead and tin may be feasible in practical applications. ${ }^{33}$ An efficiency of $4.18 \%$ was obtained for the device using the $x=0.5$ material. ${ }^{33}$ However all devices here were fabricated using a hole transport medium optimised for the shallow valence bands of the materials containing tin. ${ }^{33}$ The optimised $\mathrm{MAPbI}_{3}$ device displayed an effi- 
ciency of $11.98 \%{ }^{33}$ In an effort to use inorganic $\mathrm{CsSnI}_{3}$ as a solar absorber, which displays metallic character, $\mathrm{SnF}_{2}$ was added to the precursor solution before deposition. ${ }^{34}$ This was thought to effectively manage the vacancies present in material due to the $\mathrm{Sn}^{4+}$ oxidation product. ${ }^{34}$ However, despite this significant amount of effort towards less toxic materials, a study analyzing $\mathrm{PbI}_{2}$ and $\mathrm{SnI}_{2}$, as the primary degradation products of $\mathrm{MAPbI}_{3}$ and $\mathrm{MASnI}_{3}$, respectively, showed a higher degree of toxicity in aquatic environments for $\mathrm{SnI}_{2} \cdot{ }^{36}$ Clearly, simply replacing the ion considered to be toxic does not account for the overall toxicity of the material, and comprehensive studies must be carried out on the resulting materials.

\subsection{Nanocrystals of Metal Halide Perovskite Materials}

\subsubsection{Synthesis and Properties of Nanocrystals}

Nanocrystals represent a broad range of materials with properties that are tunable via size and shape modifications. ${ }^{37}$ These materials are generally $1-100 \mathrm{~nm}$ in size, and stabilized in solution via surface ligands bound to the surface. ${ }^{37}$ The quantum size effect causes a continuous change in electronic structure when transitioning between a bulk material and nanoparticle. ${ }^{38}$. This effect is observed optically as the physical dimensions of a crystal approach the exciton Bohr radius,

$$
a_{B}=\frac{\hbar \epsilon}{e^{2}}\left[\frac{1}{m_{n}^{*}}+\frac{1}{m_{p}^{*}}\right]
$$

where $\hbar$ is the reduced Plank constant and $\epsilon$ is the dielectric constant of the material. ${ }^{39}$ The physical confinement of the exciton results in quantized energy levels and a corresponding increase in bandgap, as would be expected with a fewer number of atomic orbitals now contributing to the energy levels of the material with respect to the bulk. ${ }^{38}$

Nanocrystals are now commonly synthesized in a solution based colloidal form. ${ }^{37,40}$ 
This offers many advantages to both the quality of the crystals, and subsequent processing for use in applications. ${ }^{40,41}$ The hot-injection technique, first introduced in 1993 for the synthesis of CdS, CdSe and CdTe nanocrystals, is now also used for metal halide perovskite nanocrystals such as $\mathrm{CsPbI}_{3} \cdot{ }^{40,42}$ Here, precursors are injected into a hot solvent containing coordinating ligands, which results in a supersaturated solution of the desired product. ${ }^{40}$ This supersaturation is relieved in solution via a burst of nucleation. ${ }^{40}$ While ligands surrounding the crystal sterically prevent other atoms from approaching and allowing crystal growth, adsorption and desorption of these ligands allow periodic access to the surface. ${ }^{40}$ After the synthesis is complete, the growth solution may be selectively processed to obtain particles with narrow size distributions. ${ }^{40}$ Often, ligands are long chain organic molecules with a functional group capable of binding to the surface of the crystal such as tri-n-octylphosphine (TOP), where the hydrophobic tail extending away from the crystal allows solubility of the crystals in non-polar solvents. ${ }^{40}$ Gradually adding a polar solvent to the solution affects the interaction between solvent and ligand, causing particles to become unstable in solution. ${ }^{40}$ As this effect is dependent on crystal size, this allows fractions of particles to be collected with very narrow size distributions during subsequent additions of the polar solvent. ${ }^{40}$

\subsubsection{Lead Halide Perovskite Nanocrystals}

Recently, interest in the lead halide perovskite materials has extended to nanocrystal synthesis for use in optoelectronic applications such as photovoltaics and lightemitting devices. ${ }^{12,42,43}$ In 2015, colloidal nanocrystals of $\mathrm{CsPbX}_{3}$ (X = I, Br, Cl) were synthesized using the hot injection method, which resulted in highly luminescent, cubic particles. ${ }^{42}$ Quantum confinement in these crystals was confirmed through observation of a shift in the absorption and emission energies due to size variation. ${ }^{42}$ High quantum yields of $50-90 \%$ and narrow photoluminescence (PL) 
line widths between $12 \mathrm{~nm}$ and $42 \mathrm{~nm}$ were attributed to the stoichiometric nature of the crystals, resulting in low concentrations of point defects. ${ }^{42}$ Subsequent experiments revealed that the halide ratio of these nanocrystals could be tuned not only through the stoichiometry of the starting materials, but also through postsynthetic ion exchange reactions. ${ }^{44}$ Partial and complete ion exchanges between halide ions were achieved through addition of lead halide salts to a solution of previously synthesized nanocrystals. ${ }^{44}$ Additionally, ion exchange between nanocrystals with different halide compositions was observed through the shift and merging of the PL peaks of the two starting materials. ${ }^{44}$ Throughout these reactions, the emission intensities, lattice structure and shape of the original nanocrystals were retained. ${ }^{44}$ Nanowires of the same composition were synthesized by varying the duration of the reaction from seconds to 90 minutes. ${ }^{43}$ The nanocubes found for short reaction times were found to evolve into the nanowires via one-dimensional attachment of the cubes. ${ }^{43}$ Nanoplatelets have also been formed through variations in reaction stoichiometry, specifically octylammonium (OA), which acts as a surface ligand, and MA. ${ }^{45}$ When only $\mathrm{OA}$ was added to the reaction flask, sheets of $\mathrm{PbX}_{6}$ octahedra formed. ${ }^{45}$ As the concentration of MA increased, the thickness of the sheets increased, allowing the quantum confinement to be monitored as a function of the number of octahedral layers in the platelet. ${ }^{45}$ 


\section{Methods}

\subsection{Synthesis Procedures}

\subsubsection{Thin Film Deposition}

Thin film deposition via spin-coating is a common and inexpensive method for initial experimental trials. A spin coating program defines the conditions of the deposition, with respect to the revolutions per minute (rpm) of the substrate, the acceleration of the substrate to this desired rpm and the duration of the program. There are three general steps involved in a spin coating deposition, illustrated in Fig. 2.1. Step 1 involves dropping the precursor solution onto the stationary substrate. Step 2 occurs as the substrate is spinning. Here, additional solution or solvent may be deposited onto the substrate if desired. Step 3 involves evaporation of the solvent from the thin film. Depending on the solvent used, this may be achieved at room temperature, or the film may be annealed at an elevated temperature. This technique may be carried out under ambient conditions, or in a nitrogen filled glovebox.

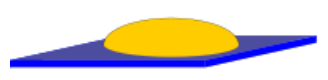

Step 1

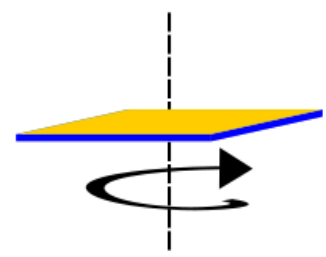

Step 2

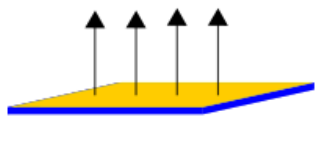

Step 3

Figure 2.1: Spin coating a thin film on a substrate involves depositing a solution while the substrate is stationary (step 1) and/or rotating (step 2), followed by solvent evaporation (step 3). 


\subsubsection{Hot Injection Nanocrystal Synthesis}

In the hot injection method for nanocrystal synthesis, precursors are prepared separately in order to accurately control the conditions under which the reaction begins and proceeds to completion. Generally, a reaction flask containing a precursor, ligands and solvent is degassed and heated to a desired temperature under nitrogen. A solution of a second precursor is then quickly injected into the flask, which produces a supersaturated solution of the desired product. ${ }^{40}$ This supersaturation is relieved by burst nucleation of the product within the solution. ${ }^{40}$ Growth of these crystals occurs as the remaining atoms of the precursors attach to the nuclei. ${ }^{40}$ The reaction is quenched by lowering the temperature of the growth solution with a water bath. Particles may be collected by centrifuging the solution with or without anti-solvent. If anti-solvent is not used, the nanocrystal mass is assumed to be heavier than any residual precursor particles or ligands, which remain in the solution during centrifuging, while the particles are collected as a solid. Anti-solvent may be used to help this process, as the addition of a solvent of opposite polarity to the nanocrystal ligand causes these ligands to contract and the particles to aggregate in the solution. ${ }^{40}$ Centrifuging the particles may be done multiple times, depending on the purity required and the stability of the nanocrystals.

\subsection{Characterization Procedures}

\subsubsection{Ultraviolet-Visible Absorbance Spectroscopy}

Ultraviolet-Visible absorbance (UV-Vis) spectroscopy is used to analyze the optical properties of thin films and solutions, where the absorbance of a sample is obtained as a function of incident wavelength. For solutions, a spectrum of a cuvette and solvent is subtracted from all subsequent spectra. The sample itself is diluted in 
the same solvent used in the blank. For thin films, a blank spectrum is taken of the substrate and subtracted from all subsequent spectra of the film. The bandgap of semiconductor materials may be determined by analyzing the UV-Vis spectrum with a Tauc plot through the formula,

$$
(\alpha h \nu)^{1 / n}=A\left(h \nu-E_{g}\right)
$$

where $\alpha$ is the absorption coefficient, $h$ is Plank's Constant, $\nu$ is the frequency of incident radiation, $A$ is a proportionality constant, $E_{g}$ is the bandgap and $n=$ 1/2 and 2 for direct and indirect bandgaps, respectively. ${ }^{46} \mathrm{~A}$ plot of energy, in $\mathrm{eV}$, versus $(\alpha h \nu)^{1 / n}$ allows determination of the bandgap through extrapolation of the band edge to the x-axis. ${ }^{46}$ If the nature of the transition is not known, the energy may be plotted against both $(\alpha h \nu)^{1 / 2}$ and $(\alpha h \nu)^{2} \cdot{ }^{46}$ The transition type may be determined by the quality of the linear fit to the band edge in the spectrum. ${ }^{46}$

\subsubsection{Photoluminescence Spectroscopy}

Photoluminescence (PL) spectroscopy is a complimentary technique to UV-Vis absorbance spectroscopy. Here, the material in solution or thin film form is excited by monochromatic radiation. While analyzing semiconductors, this radiation creates electron-hole pairs if it has an energy higher than the bandgap. ${ }^{1}$ Upon relaxation, the electron and hole may recombine through different mechanisms. ${ }^{1}$ If the excess energy is given off through the emission of light, PL spectroscopy is able to detect the wavelength and intensity with which this occurs.

\subsubsection{X-ray Diffraction}

X-ray diffraction (XRD) is used to analyze the crystal structure of a material. ${ }^{6}$ In a typical experiment, the angle of incidence is plotted against the resulting 


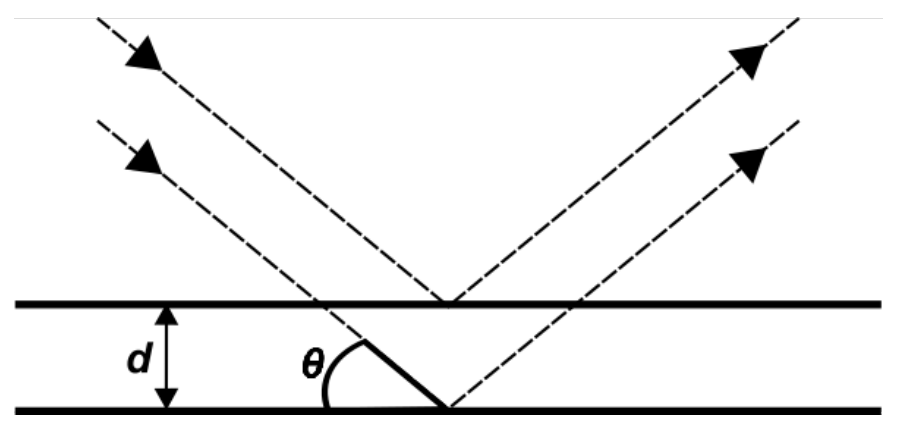

Figure 2.2: Reflection of X-ray radiation off 2 adjacent planes in a lattice. Constructive interference occurs if the difference between path lengths is an integral multiple of the wavelength.

intensity of the reflected beam. The incident radiation interacts with electrons in the lattice, and produces characteristic spectra for a given material. ${ }^{6}$ However, equivalent spectra are obtained if it is assumed that the lattice consists of sets of planes throughout the crystal. ${ }^{6}$ For each set of parallel planes, there is a defined interplanar distance, $d$, between adjacent planes. ${ }^{6}$ Two incoming beams may reflect off two different planes within the same set, and the resulting reflected beams will interfere constructively or destructively, based on the angle of incidence, $\theta .{ }^{6}$ This process is shown in Fig. 2.2. The condition for constructive interference, and therefore measureable intensity, of the reflected beams is given by

$$
2 d \sin \theta=n \lambda
$$

where $n$ is a positive integer and $\lambda$ is the wavelength of radiation. ${ }^{6}$

\subsubsection{Scanning Electron Microscopy}

A scanning electron microscope (SEM) allows for high resolution imaging of surfaces and objects including thin films, biological samples and nanoparticles. An electron beam is focused down a column, at the bottom of which is the sample under vacuum. As the electron beam necessarily charges the surface of the sample, 


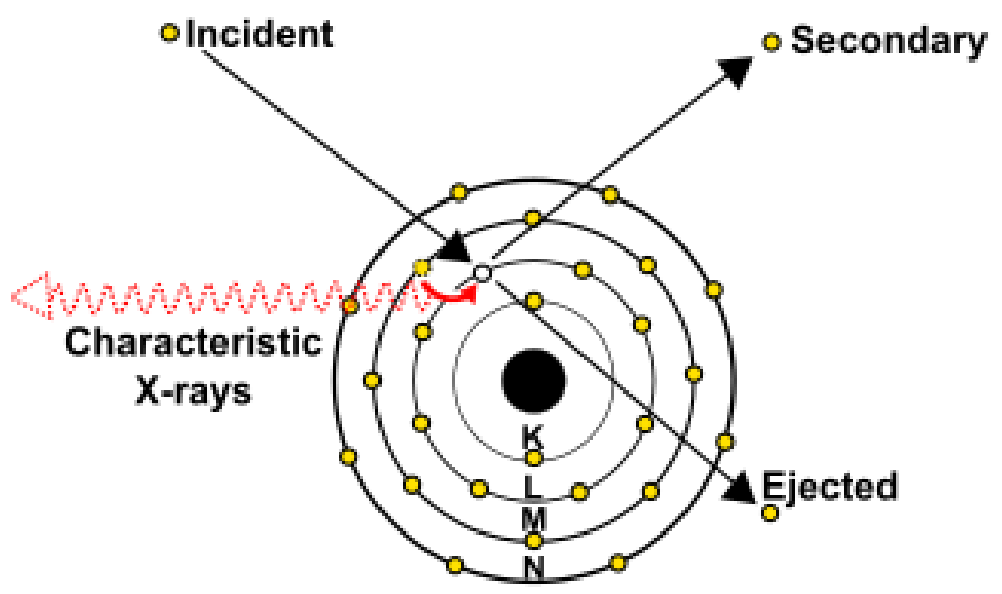

Figure 2.3: Generation of secondary electrons and characteristic X-rays during SEM analysis.

the sample itself must be conductive for successful imaging, or coated in a conductive material such as carbon or gold before analysis. Electrons interacting with a sample can result in many distinct signals, depending of the depth of penetration. ${ }^{47}$ A common way to image samples is through the detection of secondary electrons with secondary electron imaging (SEI). ${ }^{47}$ These electrons are emitted from shallow depths of approximately $2 \mathrm{~nm}$ within the sample and therefore give information concerning the morphology of the sample. ${ }^{47}$ Backscattered electrons may also be detected, which are generated at a greater depth compared to secondary electrons. ${ }^{47}$ These electrons give information concerning sample morphology in addition to compositional information, as the intensity of these electrons increases with the atomic weight. ${ }^{47}$ In addition to the emission of electrons, characteristic X-rays are also emitted from samples, as shown in Fig. 2.3. ${ }^{47}$ As the incident electron interacts with atoms of the sample, a core electron may be ejected, leaving a vacant hole. ${ }^{47}$ An electron in a higher energy level will favourably occupy this hole to achieve a lower energy. ${ }^{47}$ The excess energy is emitted as X-rays from the sample. ${ }^{47}$ Each atom has a characteristic set of X-rays which are emitted during 
this process, and this provides a method to determine the atomic composition of a sample. ${ }^{47}$ The process of collecting X-ray signals from a sample is known as Energy Dispersive Spectroscopy (EDS) and is a common feature of SEM analysis. ${ }^{47}$ This technique may also be used in a mapping mode, whereby a map of atomic densities may be compared to an SEI image, allowing correlations between morphology and atomic composition. ${ }^{47}$

\subsubsection{Transmission Electron Microscopy}

The transmission electron microscope (TEM) operates in a similar manner to the SEM. Electrons are focused down a column onto a sample. However here, the samples are thin enough to allow electrons to pass through onto a fluorescent screen or camera to be imaged. ${ }^{47}$ A higher resolution is possible using the TEM versus the SEM, such that the morphology of nanocrystals can readily be imaged. These samples are mounted onto grids, usually consisting of copper. For those samples smaller than the grid size, a carbon support mesh is used for the sample to be deposited on. As with the SEM, EDS analysis is also possible with this instrument. Scanning Transmission Electron Microscopy (STEM) is yet another analysis technique available to use with the TEM. ${ }^{47}$ This creates an atomic density map of the focused image, allowing compositional determination against a standard image. ${ }^{47}$

\subsubsection{Solar Cell Efficiency}

The performance of a solar cell is quantified by measuring the current-voltage $(I-V)$ response. In order for this measurement to provide a direct comparison of cells with varying areas, this data is commonly reported as a current densityvoltage response $(J-V)$. An example of a $J-V$ curve is shown in Fig. 2.4. These measurements are carried out while the cell is illuminated with a known intensity 


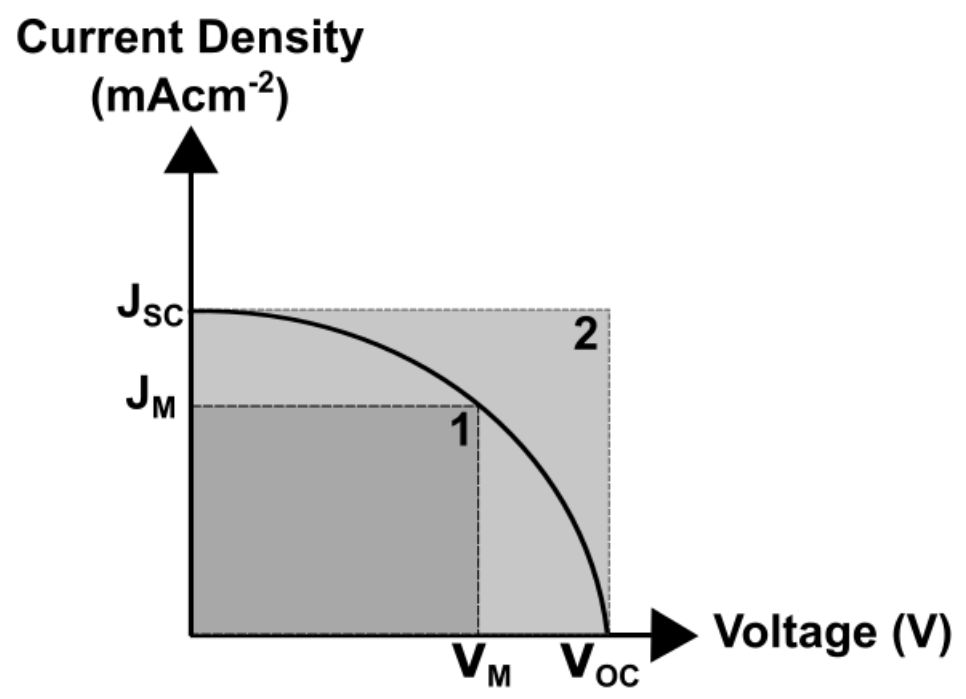

Figure 2.4: Current Density-Voltage characteristics of a photovoltaic device

of radiation, commonly $100 \mathrm{~mW} / \mathrm{cm}^{2}$. Two defining features of this curve are the short-circuit current $\left(J_{S C}\right)$ and the open-circuit voltage $\left(V_{O C}\right)$, which occur when the resistance $(R)$ is zero and $\infty$, respectively. ${ }^{1}$ The fill factor $(\mathrm{FF})$ of a solar cell is a ratio between the maximum possible power, based on the measured $J_{S C}$ and $V_{O C}$, versus the maximum power experimentally obtained. ${ }^{1}$ This is defined as the ratio of area 1 to area 2 in Fig. 2.4 which corresponds to

$$
F F=\frac{J_{m} V_{m}}{J_{S C} V_{O C}}
$$

where $J_{m}$ and $V_{m}$ are the current density and voltage that produce the maximum power output, respectively. ${ }^{1}$ Finally, the power conversion efficiency (PCE) is a parameter relating the optical power input $\left(P_{i n}\right)$ to electrical power output. ${ }^{1}$ This is defined as

$$
\eta=\frac{P_{m}}{P_{\text {in }}} \times 100 \%=\frac{J_{m} V_{m}}{P_{\text {in }}} \times 100 \%
$$

where $\eta$ is the PCE of the device. ${ }^{1}$ 


\section{Metal Ion Substitutions in Lead Halide Perovskites}

\subsection{Mixed Bismuth and Lead Halide Perovskite Thin Films}

\subsubsection{Motivation}

Recently, a new class of perovskites incorporating the $\mathrm{Bi}^{3+}$ ion has been studied as the active layer in photovoltaic devices. ${ }^{48,49,50,51,52}$ Due to the higher oxidation state of $\mathrm{Bi}^{3+}$ relative to $\mathrm{Pb}^{2+}$, the $\mathrm{ABX}_{3}$ structure is no longer a charge balanced unit upon direct substitution. The related $\mathrm{A}_{3} \mathrm{~B}_{2} \mathrm{X}_{9}$ crystal structure has been shown to crystallize from solutions containing $\mathrm{Cs}^{+}, \mathrm{Bi}^{3+}$ and $\mathrm{I}^{-} .53$ Both this material, and the organic-inorganic counterpart, $\mathrm{MA}_{3} \mathrm{Bi}_{2} \mathrm{I}_{9}$, were determined to have hexagonal symmetry. ${ }^{53,54}$ Octahedral cages within these materials are facesharing and exist as isolated $\left(\mathrm{Bi}_{2} \mathrm{I}_{9}\right)^{3-}$ clusters in the structure. ${ }^{53,54}$ Recent studies of these materials have shown favourable characteristics for photovoltaic applications including the ability to be synthesized as a thin film via solution processing and optical absorption in the visible region. ${ }^{48,49}$ A stability study comparing $\mathrm{MA}_{3} \mathrm{Bi}_{2} \mathrm{I}_{9}$ to $\mathrm{MAPbI}_{3}$ showed promising results after 26 days of storage in ambient conditions. ${ }^{49}$ While little difference was observed in the visible appearance and XRD pattern of the $\mathrm{MA}_{3} \mathrm{Bi}_{2} \mathrm{I}_{9}$ film, the majority of the $\mathrm{MAPbI}_{3}$ film degraded to $\mathrm{PbI}_{2}$ over this time period. ${ }^{49}$ These materials were first incorporated as the active layer in photovoltaic devices in 2015, where an efficiency of $1.09 \%$ was achieved using $\mathrm{Cs}_{3} \mathrm{Bi}_{2} \mathrm{I}_{9}$ as the absorbing layer, which displayed a bandgap of 2.2 eV. ${ }^{48}$ Using $\mathrm{MA}_{3} \mathrm{Bi}_{2} \mathrm{I}_{9}$, with a similar bandgap of $2.1 \mathrm{eV}$, an efficiency of $0.12 \%$ was obtained. ${ }^{48}$ The device architecture used throughout this study consisted of a mesoporous $\mathrm{TiO}_{2}$ layer as the electron transport layer and spiro-MeOTAD as the hole transport layer. ${ }^{48}$ Additional studies on devices using $\mathrm{A}_{3} \mathrm{Bi}_{2} \mathrm{X}_{9}$ materials in photovoltaic devices have reported efficiencies which have stayed within the range of $0.003 \%-1.09 \%{ }^{48,51,52}$ The goal of this study is to determine whether a 
compromise between the high efficiencies obtained with lead halide devices and the increased stability seen in bismuth halide materials can be achieved. This was found to be a successful technique when fabricating devices using $\mathrm{MASn}_{x} \mathrm{~Pb}_{1-x} \mathrm{I}_{3}$, where the maximum PCE was found at $x=0.5$ for a given device architecture. ${ }^{33}$ Here, we investigate $\mathrm{Bi}^{3+}$ incorporation into thin films of $\mathrm{MAPbI}_{3}$. Although heterovalent substitution necessarily introduces vacancies into the structure, the high defect tolerance observed for metal halide perovskites may allow for such alterations without a large impact on optical and conduction properties. ${ }^{55}$ A 2 step deposition is used for these films, where the $\mathrm{Bi}^{3+}$ is added to the material using precursor solutions of $(x) \mathrm{BiI}_{3}+(1-x) \mathrm{PbI}_{2}$. Characterization of the resulting materials is carried out through XRD, UV-Vis absorption and SEM analysis. Additionally, photovoltaic devices are fabricated using these materials and PCEs are compared to that obtained for a device using pure $\mathrm{MAPbI}_{3}$.

\subsubsection{Methods}

Device Fabrication: Pre-etched fluorine doped tin oxide (FTO) substrates were cleaned in ultrasonic baths of Micron 90 (Sigma Aldrich), deionized water, acetone and isopropanol for 20 minutes per solution. The substrates were then oxygen plasma cleaned for 3 minutes. A compact $\mathrm{TiO}_{2}$ layer was deposited via spincoating titanium diisopropoxide bis(acetylacetonate) (Sigma Aldrich, $75 \mathrm{wt} \%$ in isopropanol), diluted to $0.15 \mathrm{M}$ in 1-butanol, at $4000 \mathrm{rpm}$ for $40 \mathrm{~s}$. The substrate was dried at $125{ }^{\circ} \mathrm{C}$ for 5 min. A mesoporous $\mathrm{TiO}_{2}$ layer was deposited via spin-coating $\mathrm{TiO}_{2}$ paste (DYESOL, DSL18NR-T), diluted in ethanol in a 2:7 $\mathrm{w} / \mathrm{w}$ ratio, at $4000 \mathrm{rpm}$ for $40 \mathrm{~s}$. The substrate was dried at $125{ }^{\circ} \mathrm{C}$ for $5 \mathrm{~min}$ and annealed at $500{ }^{\circ} \mathrm{C}$ for $30 \mathrm{~min}$. For a two-step deposition of the perovskite layer, a $1 \mathrm{M}$ solution of $(x) \mathrm{BiI}_{3}+(1-x) \mathrm{PbI}_{2}$ in $\mathrm{DMF}$ was stirred at $70{ }^{\circ} \mathrm{C}$ and deposited via spin-coating at $5000 \mathrm{rpm}$ for $40 \mathrm{~s}$. This film was dried at $70{ }^{\circ} \mathrm{C}$ 
for $10 \mathrm{~min}$. During a $60 \mathrm{~s}$ spin-coating program at $1500 \mathrm{rpm}$, a $10 \mathrm{mg} / \mathrm{mL}$ solution of MAI (DYESOL) in isopropanol was drop-cast on the substrate for a total of $20 \mathrm{~s}$. The film was annealed at $100{ }^{\circ} \mathrm{C}$ for $30 \mathrm{~min}$. For deposition of the hole transport layer, $28.8 \mu \mathrm{L}$ of 4-tert-butylpyridine (Sigma Aldrich, 96\%) and $17.5 \mu \mathrm{L}$ of a $520 \mathrm{mg} / \mathrm{mL}$ solution of Bis(trifluoromethane) sulfonimide lithium salt (Sigma Aldrich) was added to a $1 \mathrm{~mL}$ solution containing $72.3 \mathrm{mg}$ 2,2',7,7'-tetrakis(N,N-di-p-methoxyphenylamine)9,9'-spirobifluorene (Lumtec). This solution was deposited on the substrate via spin-coating at $4000 \mathrm{rpm}$ for $40 \mathrm{~s}$. Deposition of the perovskite and hole transport layers were done in a nitrogen filled glovebox. $100 \mathrm{~nm}$ of silver was evaporated as a top electrode.

Device Characterization: Structural characterization of the thin films was carried out via X-ray diffraction (PANalytical X'Pert Pro Multi Purpose Diffractometer) using $\mathrm{Cu} \mathrm{K} \alpha$ radiation at $40 \mathrm{kV}$ and $45 \mathrm{~mA}$. A baseline correction was applied to the spectra, to remove the amorphous substrate signal present in all scans. SEM analysis (JEOL 6500F) at $20 \mathrm{kV}$ was used to determine film morphology. UV-Visible absorption spectroscopy (Varian Cary 50 Spectrophotometer) of the thin films was used to determine optical characteristics. A background scan was subtracted from all scans using a substrate composed of FTO and $\mathrm{TiO}_{2}$. Currentvoltage characteristics of the devices were measured (Keithley 236 Source Measure Unit) while illuminated with AM 1.5G irradiation using a xenon-lamp solar simulator (Sciencetech, 500-IG). The irradiation was calibrated to $100 \mathrm{~mW} / \mathrm{cm}^{2}$ using a standard solar cell (VLSI Standards Incorporated, SN 10510-0368). All device measurements were carried out in ambient conditions. 


\subsubsection{Results and Discussion}

Fig. 3.1 shows XRD patterns of thin films on a mesoporous $\mathrm{TiO}_{2}$ scaffold using a 2 step deposition method, where asterisk indicate FTO and $\mathrm{TiO}_{2}$ substrate peaks. Comparison of the experimental data with a $\mathrm{MAPbI}_{3}$ reference pattern (PDF Number 01-083-7582) shows agreement for the $x=0$ and $x=0.05$ films, with no impurity peaks visible. The expected peak splitting caused by the tetragonal $\mathrm{MAPbI}_{3}$ unit cell is largely unresolved here, although confirmed by observation of the $\langle 211\rangle$ and $\langle 202\rangle$ planes at $2 \theta=23.47657^{\circ}$ and $24.52957^{\circ}$. In a cubic cell, these planes have equal interplanar spacing and form the $\langle 111\rangle$ plane. ${ }^{56}$ Although the $\mathrm{ABX}_{3}$ structure does not appear to be altered by replacing $5 \%$ of the $\mathrm{Pb}^{2+}$ ions with $\mathrm{Bi}^{3+}$, cation vacancies are expected to be present due to the addition of excess positive charge. For the $x=0.5$ thin film, significant impurity peaks are visible in the spectra, in addition to the perovskite peaks. Comparison with a $\mathrm{Cs}_{3} \mathrm{Bi}_{2} \mathrm{I}_{9}$ pattern (PDF Number 00-023-0847) shows agreement with these impurities. In the absence of reference data for $\mathrm{MA}_{3} \mathrm{Bi}_{2} \mathrm{I}_{9}$, this is a suitable comparison because the compounds crystallize in the same structure, with only slight shifts of $2 \theta$ in XRD patterns. ${ }^{48}$ Therefore, based on the MA cation used in synthesis, this phase is identified as $\mathrm{MA}_{3} \mathrm{Bi}_{2} \mathrm{I}_{9}$. Rather than form cation vacancies in the structure, it appears that additional uptake of MAI during spin coating is preferred to create a two phase material. For the $x=1$ thin film, which has no $\mathrm{Pb}^{2+}$ in the precursor solution, there are no longer any peaks indicating the tetragonal perovskite phase. Morphology changes of the films are observed via SEM imaging and shown in Fig. 3.1. A change in crystallization is observed for all levels of $\mathrm{Bi}^{3+}$ substitution, which agrees with the XRD analysis. If the thin films had retained the $\mathrm{MAPbI}_{3}$ structure, one would expect a defined crystal morphology to be present in all films. However the crystallinity appears to decrease upon bismuth substitution values of $x=0.05$ and $x=0.5$, which may indicate the mixed phase material seen in the 
XRD patterns. Also, the $x=1$ sample has very different morphology to the $x=0$ sample, indicating different crystal structures. This image also qualitatively agrees with a previous study on $\mathrm{MA}_{3} \mathrm{Bi}_{2} \mathrm{I}_{9}$ thin films, where the material was observed to form as interconnected thin layers via SEM imaging. ${ }^{48}$

$\mathrm{UV}$-Vis absorption spectra of these films show significant variations in the onset and relative degree of absorption between 500 and $900 \mathrm{~nm}$. While previous studies of metal ion substitution reported shifts in the absorption onset, sharp absorption edges were maintained throughout the substitution range. ${ }^{28,33}$ However, as shown in Fig. 3.2, the sharp absorption onset of $\mathrm{MAPbI}_{3}$ is lost upon addition of $5 \% \mathrm{BiI}_{3}$ to the precursor solution. Increasing the $\mathrm{Bi}^{3+}$ concentration to $x=0.5$ results in weak absorptions between 650 and $1000 \mathrm{~nm}$, before an increase in absorption
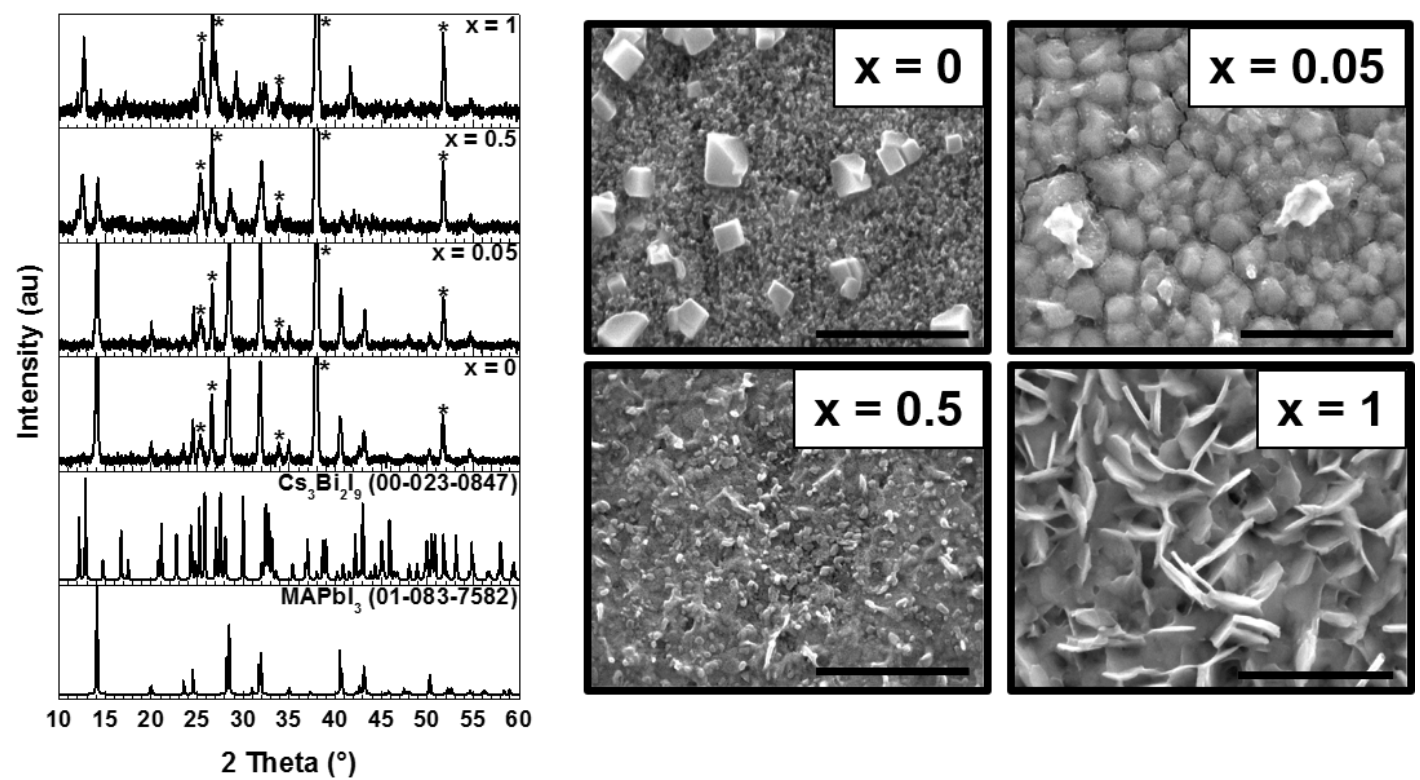

Figure 3.1: (Left) XRD patterns of thin films, where $\mathrm{x}$ refers to the stoichiometry of the precursor solution: $x \mathrm{BiI}_{3}+(1-x) \mathrm{PbI}_{2}$. Asterisk mark the FTO and $\mathrm{TiO}_{2}$ substrate. (Right) SEM images of thin films corresponding to the XRD patterns, as labelled. The scale bar corresponds to $0.5 \mu \mathrm{m}$. 

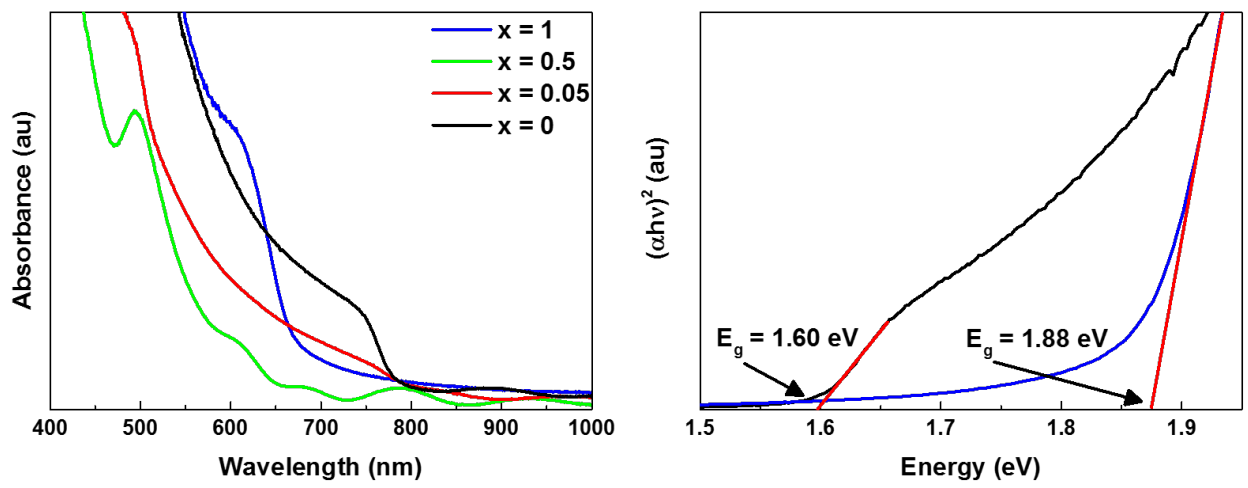

Figure 3.2: (Left) UV-Vis absorption of thin films, where $\mathrm{x}$ refers to the stoichiometry of the precursor solution: $x \mathrm{BiI}_{3}+(1-x) \mathrm{PbI}_{2}$. (Right) Tauc plots of the $\mathrm{x}=$ 0 and $\mathrm{x}=1$ absorption spectra, assuming a direct bandgap.

comparable to the $x=0$ film is seen at approximately $650 \mathrm{~nm}$. These features of the $x=0.05$ and $x=0.5$ films may be a result of overlapping spectra due to a mixed phase film, or trap states due to impurities not discernable through XRD. A sharp absorption onset is regained for the $x=1$ film. Tauc plots were constructed from the $x=0$ and $x=1$ spectra and are shown in Fig. 3.2 as well. Assuming a direct bandgap, $E_{g}$ values of $1.60 \mathrm{eV}$ and $1.88 \mathrm{eV}$ are obtained for the $x=0$ and $x=1$ films, respectively. The bandgap of $1.60 \mathrm{eV}$ is in agreement with previous reports of $1.5 \mathrm{eV}$ and $1.55 \mathrm{eV}$ for $\mathrm{MAPbI}_{3} \cdot{ }^{4,21}$ Studies of the $\mathrm{MA}_{3} \mathrm{Bi}_{2} \mathrm{I}_{9}$ material have reported direct bandgap values of $2.1 \mathrm{eV}$ and $2.4 \mathrm{eV}$, and indirect bandgap values of 2.04 and $2.1 \mathrm{eV} \cdot{ }^{48,49,57}$ Given this variance of $0.36 \mathrm{eV}$, the bandgap of $1.88 \mathrm{eV}$ determined here may be acceptable. ${ }^{58}$

Solar cell devices using these materials were fabricated to test the influence of bismuth substitution on performance as measured through J-V curves. These are shown in Fig. 3.3, with the PCE, $V_{O C}, J_{S C}$ and $\mathrm{FF}$ values listed within the graphs. As little as $5 \%$ bismuth addition into the $\mathrm{MAPbI}_{3}$ structure has drastic effects on the performance as seen by the drop in PCE by three orders of magnitude. 
The drop in $J_{S C}$ itself indicates that relatively few charges are able to be collected by the $\mathrm{TiO}_{2}$ or spiro-MeOTAD upon substitution. This could be a result of the multiphase thin film itself, for the $x=0.05$ and $x=0.5$ devices. Consideration of previously reported band structures of $\mathrm{MAPbI}_{3}$ and $\mathrm{MA}_{3} \mathrm{Bi}_{2} \mathrm{I}_{9}$ shows that the bandgap of $\mathrm{MAPbI}_{3}$ lies within that of $\mathrm{MA}_{3} \mathrm{Bi}_{2} \mathrm{I}_{9} \cdot{ }^{22,50}$. Therefore, absorption of optical energy by the $\mathrm{MAPbI}_{3}$ will create electron-hole pairs that are unable to be transferred to the $\mathrm{MA}_{3} \mathrm{Bi}_{2} \mathrm{I}_{9}$ phase. Within the device, if contact between $\mathrm{MAPbI}_{3}$ and $\mathrm{TiO}_{2}$ is physically blocked by $\mathrm{MA}_{3} \mathrm{Bi}_{2} \mathrm{I}_{9}$, this will prevent charge transfer to the electrodes and the electron-hole pair will recombine without doing electrical work. When $x=1$, this argument does not hold, however here the morphology of the film
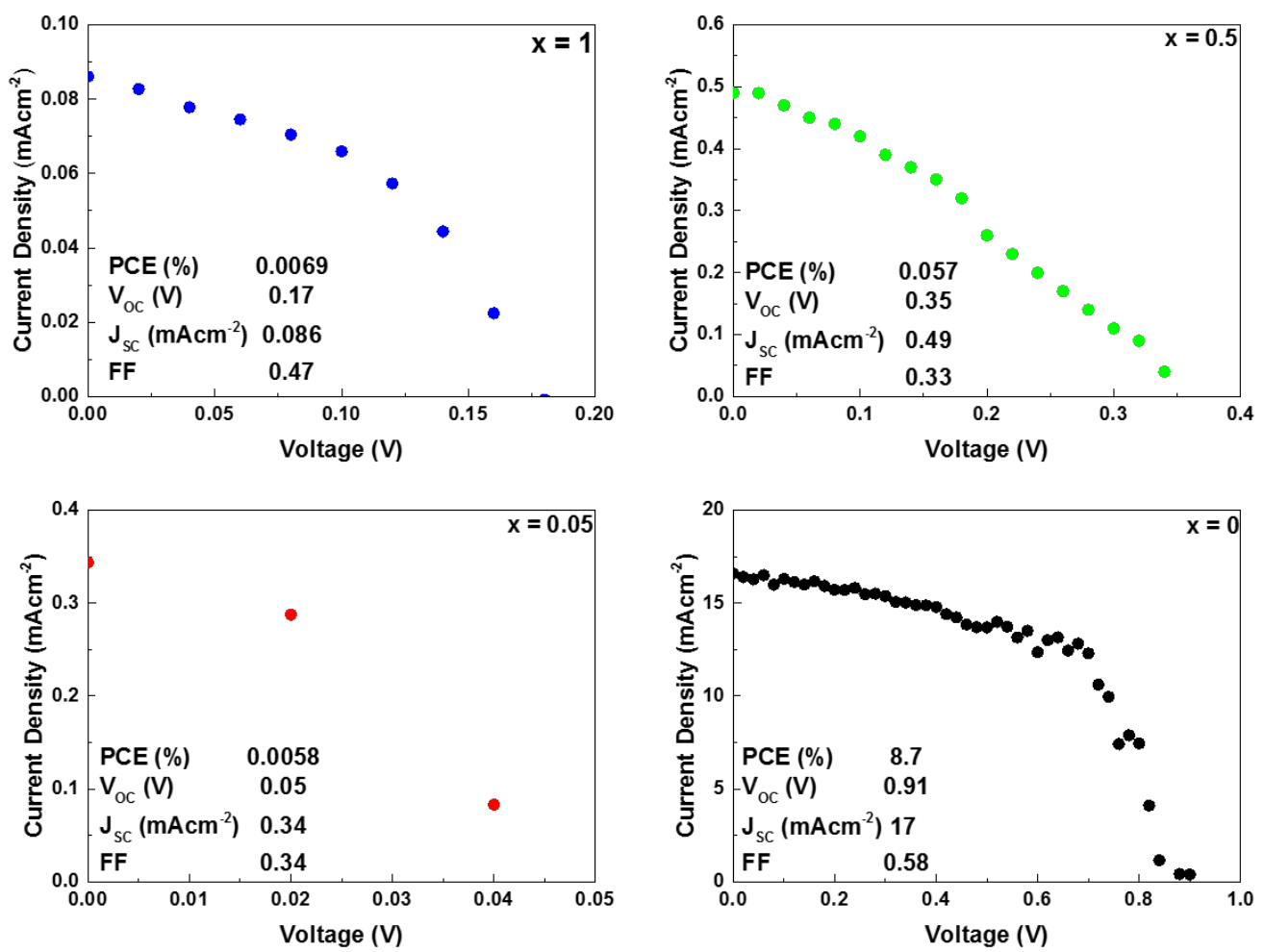

Figure 3.3: J-V curves of photovoltaic devices, where $\mathrm{x}$ refers to the stoichiometry of the precursor solution: $x \mathrm{BiI}_{3}+(1-x) \mathrm{PbI}_{2}$. $\mathrm{PCE}, \mathrm{V}_{\mathrm{OC}}, \mathrm{J}_{\mathrm{SC}}$ and FF parameters are listed within the graphs. 
may have a larger impact on device performance. High efficiencies in photovoltaic devices have often been attributed to the density of the film, which allows for more optical absorption within a given volume, and the uniformity of the film, which prevents short circuit paths between the hole and electron transport layers. ${ }^{23,24}$ For the pure bismuth halide material here, both of these characteristics may be improved upon to increase device performance, as the orientation of the crystals appears to be random. Additionally, the lack of optical absorption above 700 $\mathrm{nm}$ for this material reduces the concentration of photogenerated charge carriers compared to the $\mathrm{MAPbI}_{3}$ material.

\subsection{Bismuth and Thallium Doping in $\mathrm{MAPbI}_{3}$}

\subsubsection{Motivation}

As substitutions of $\mathrm{Bi}^{3+}$ in $\mathrm{MAPbI}_{3}$ over a wide range of compositions did not show improvements in the optoelectronic properties of the materials with respect to absorption or device efficiencies, this project moved towards substitutions in the dopant range. As described in Sec. 1.3, there have been many studies relating homovalent substitutions in metal halide perovskites to changes in material properties. ${ }^{28,29,9,27,32,33,34}$ However heterovalent doping appears to be limited to one report where $\mathrm{Bi}^{3+}$ and $\mathrm{Au}^{3+}$ were successfully doped into $\mathrm{MAPbBr}_{3}$ single crystals. ${ }^{59}$ Although $\mathrm{Au}^{3+}$ did not have an impact on the optical properties of the crystals, incorporation of $\mathrm{Bi}^{3+}$ caused a red-shift in the onset of optical absorption. ${ }^{59}$ For a dopant concentration of $0.120 \%$, a shift of $110 \mathrm{~nm}$ was observed, corresponding to a narrowing of the bandgap from $2.17 \mathrm{eV}$ to $1.89 \mathrm{eV}{ }^{59}$ This was thought to be due to either the change of covalency and bond angle of the metal halide bond, or the large number of dopant states overlapping with the conduction band of $\mathrm{MAPbBr}_{3} \cdot{ }^{5,31,59,60}$ As the energy of the valence band did not shift sig- 
nificantly compared to the conduction band, the doped material was determined to be n-type, which was also confirmed through determination of electrons as the majority charge carrier. ${ }^{59}$ Here, we study whether this bandgap narrowing can be achieved in thin films of metal halide perovskites and fabricate devices to determine the effect this may have on the PCE, $V_{O C}, J_{S C}$ and $\mathrm{FF}$ parameters of the cells. Both $\mathrm{Bi}^{3+}$ and $\mathrm{Tl}^{+}$are added to the perovskite $\mathrm{MAPbI}_{3}$ at dopant concentrations of $0.1 \%, 0.5 \%$ and $1.0 \%$. The ionic radii of $\mathrm{Pb}^{2+}, \mathrm{Bi}^{3+}$ and $\mathrm{Tl}^{+}$are

$1.29 \AA, 1.17 \AA$ And $1.59 \AA$, respectively. ${ }^{61}$ These radii result in tolerance factors of $0.885,0.917$ and 0.815 for occupation of $\mathrm{Pb}^{2+}, \mathrm{Bi}^{3+}$ and $\mathrm{Tl}^{+}$in the $\mathrm{B}$ site of the $\mathrm{ABX}_{3}$ structure, respectively, when $\mathrm{MA}^{+}$is the $\mathrm{A}$ site cation and $\mathrm{I}^{-}$is the halide anion. ${ }^{10,61}$ These tolerance factors are within the range known to form the $\mathrm{ABX}_{3}$ structure. ${ }^{62}$ In addition to room temperature device measurements, this project also involves low temperature field-effect transistor measurements to determine the effect on charge carriers and mobility these modifications have. Ionic transport within metal halide perovskites has been found to screen charge carrier mobilities at room temperature, which prevents a complete understanding of transport within the material. ${ }^{63,64}$ Unfortunately, at the time of writing the equipment to carry out low temperature measurements was not yet operational, and so these studies are delayed for future work.

\subsubsection{Methods}

Device Fabrication: Photovoltaic devices were fabricated as outlined in section 3.1.2. For bismuth doped materials, the metal halide solution had a composition of $(x) \mathrm{BiI}_{3}+(1-x) \mathrm{PbI}_{2}$. For thallium doped materials, the metal halide solution had a composition of $(x) \mathrm{Tl}\left(\mathrm{CH}_{3} \mathrm{COO}\right)+(1-x) \mathrm{PbI}_{2}$.

Device Characterization: XRD, UV-Vis absorption, and $J-V$ measurements 
were carried out as outlined in section 3.1.2.

\subsubsection{Results and Discussion}

XRD patterns of the thin films are shown in Fig. 3.4, where the asterisk denote unreacted $\mathrm{PbI}_{2}$. As in Sec. 3.1.3, the perovskite structure is confirmed for the $x=$ 0 sample upon comparison to a $\mathrm{MAPbI}_{3}$ reference (PDF Number 01-083-7582). As $\mathrm{Bi}^{3+}$ and $\mathrm{Tl}^{+}$are added to the material, no impurity peaks appear in the XRD patterns. While this could indicate that any impurities are not concentrated enough to appear in this analysis, it does indicate that the bulk properties of the material have not changed significantly. Fig. 3.5 shows the optical absorption properties of

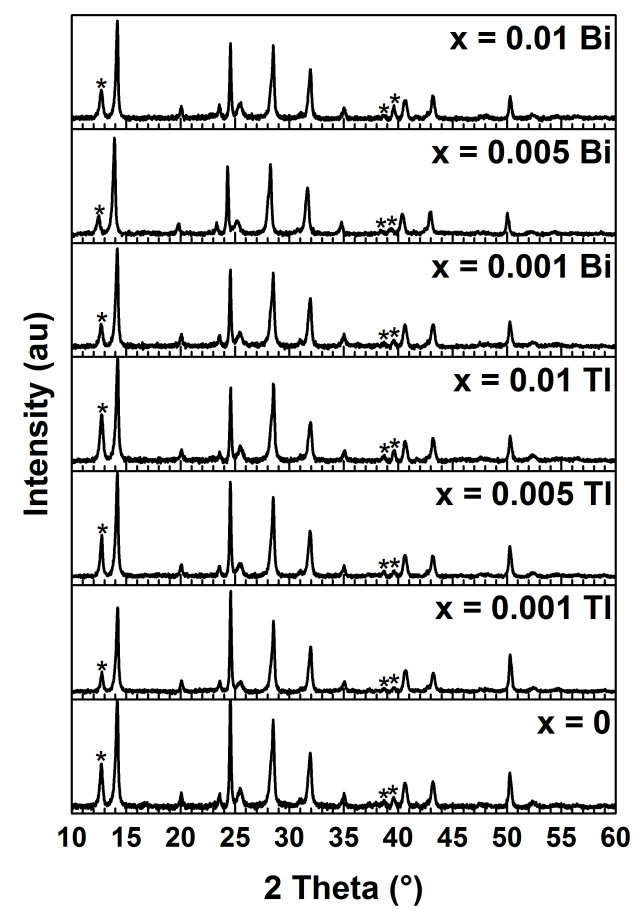

Figure 3.4: XRD patterns of $\mathrm{Bi}^{3+}$ or $\mathrm{Tl}^{+}$doped $\mathrm{MAPbI}_{3}$ thin films, as labelled. The asterisk denotes unreacted $\mathrm{PbI}_{2}$ in the films. 

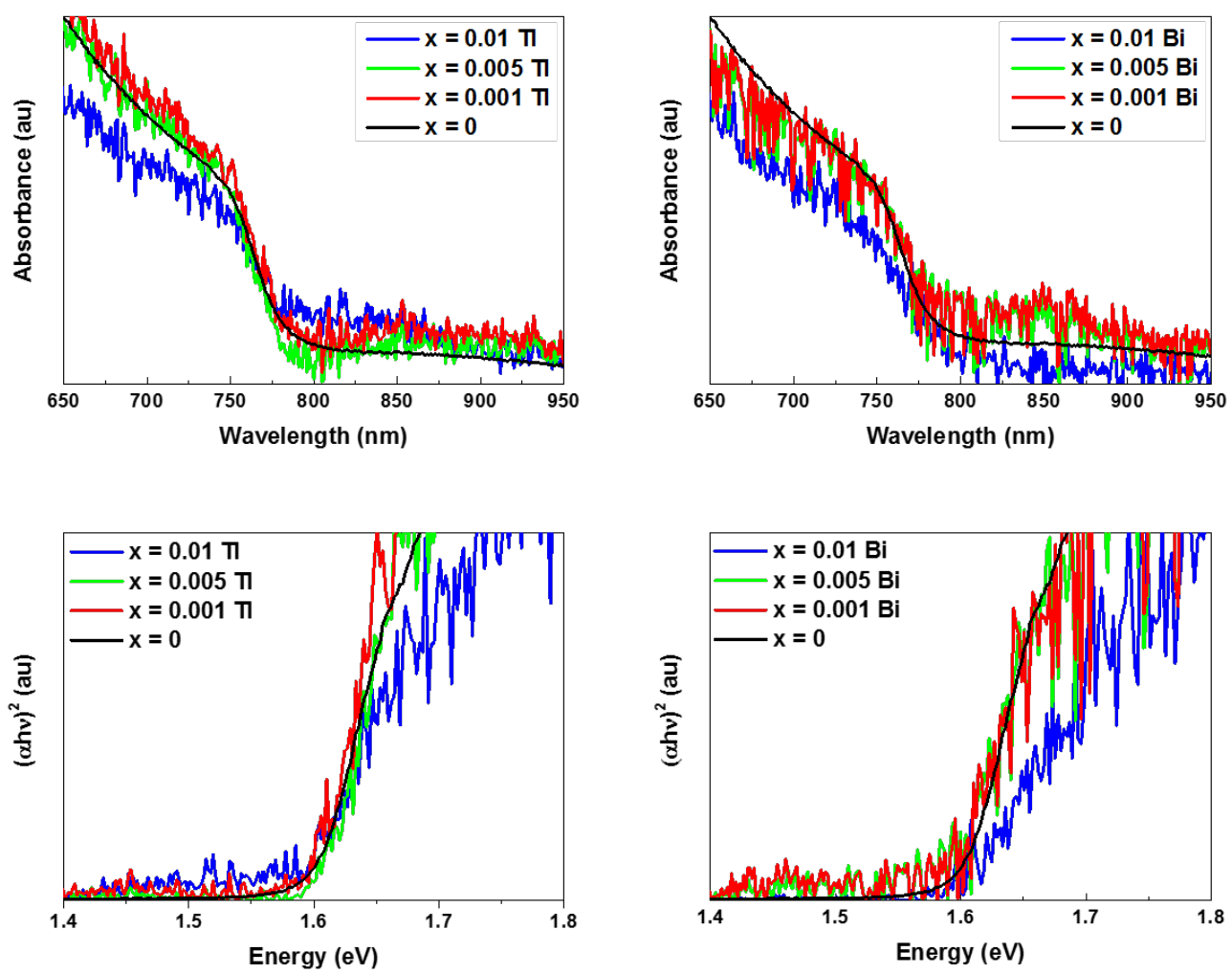

Figure 3.5: (Top) UV-Vis absorption of $\mathrm{Bi}^{3+}$ or $\mathrm{Tl}^{+}$doped $\mathrm{MAPbI}_{3}$ thin films, as labelled. (Bottom) Corresponding Tauc plots, assuming a direct bandgap for all materials.

the films. Upon addition of the dopants to the thin films, the onset of absorption does not appear to change significantly from the $\mathrm{MAPbI}_{3}$ control sample. However there is some low energy absorption in the spectra, most significantly for the $x$ $=0.005$ and $x=0.001$ samples of the $\mathrm{Bi}^{3+}$ films. This could be a result of the high degree of scattering in these spectra, however could also point to trap states within the material as a consequence of the dopant. The corresponding Tauc plots, assuming a direct bandgap in accordance to previous reports, reveal that the bandgap of all the samples stays within 1.58-1.61 eV, with no trend observed for increasing dopant concentrations. ${ }^{4,30}$ This range is much smaller than that seen 

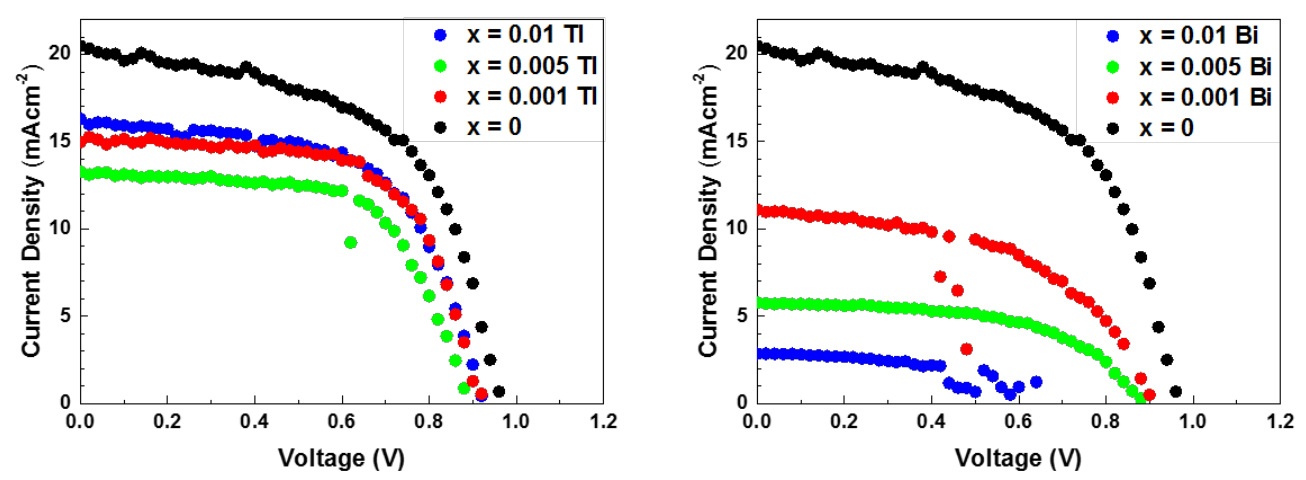

Figure 3.6: J-V curves of photovoltaic devices fabricated with $\mathrm{Bi}^{3+}$ or $\mathrm{Tl}^{+}$doped $\mathrm{MAPbI}_{3}$, as labelled.

for incorporation of $\mathrm{Bi}^{3+}$ in single crystals, and may indicate that the ions are not residing in the lattice site of the perovskite. ${ }^{59}$

Photovoltaic devices were fabricated using these films as the absorbing layer to determine the effect of the dopants on device performance. The J-V curves of the champion device for each dopant level are shown in Fig. 3.6. From these curves alone, it is apparent that the addition of $\mathrm{Bi}^{3+}$ into the precursor solutions has a more significant effect on device performance versus $\mathrm{Tl}^{+}$. The $\mathrm{Tl}^{+}$doped devices maintain $V_{O C}$ values comparable to the $\mathrm{MAPbI}_{3}$ device. However, a decrease in $J_{S C}$ occurs for all dopant levels, without a trend arising with respect to dopant concentration. The occurrence of a TII precipitate may be responsible for this, due to the addition of the $\mathrm{PbI}_{2}$ salt to the $\mathrm{Tl}\left(\mathrm{CH}_{3} \mathrm{COO}\right)$ solution. As all solutions are filtered before deposition, the amount of $\mathrm{Tl}\left(\mathrm{CH}_{3} \mathrm{COO}\right)$ weighed may not be representative of the final concentration in the film. However, as shown in Fig. 3.7, the decrease in $J_{S C}$ upon addition of $\mathrm{Tl}^{+}$is consistent across a range of seven devices, indicating that the dopant was successfully introduced to the material at some concentration. A trend with respect to device performance is clearly observed for the $\mathrm{Bi}^{3+}$ devices, where both the $V_{O C}$ and $J_{S C}$ decrease with increasing dopant 

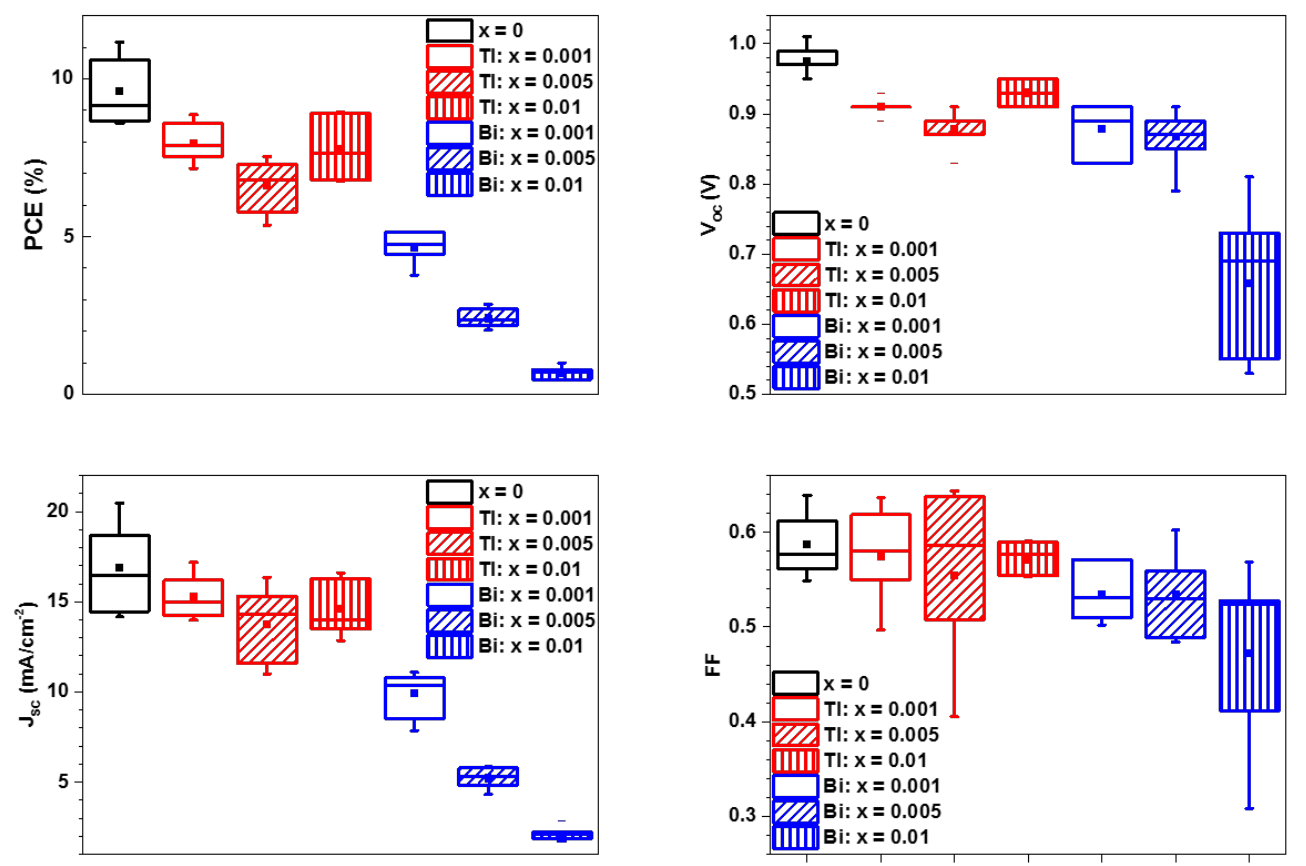

Figure 3.7: Photovoltaic cell parameters versus dopant concentration, for photovoltaic devices fabricated with $\mathrm{Bi}^{3+}$ or $\mathrm{Tl}^{+}$doped $\mathrm{MAPbI}_{3}$, as labelled. The bars represent the minimum and maximum of each data set, the upper and lower limits of the box represent the third and first quartile, respectively, and the filled squares represent the mean value.

concentration. As with the $\mathrm{Bi}^{3+}$ substitutions, the device is not able to effectively separate photogenerated charges. In contrast with the substitutions, the optical absorption edges of the material has not changed significantly. This indicates that there may be deep trap states in the bandgap of the material due to this dopant, and the photogenerated electrons do not have sufficient energy to be promoted to the conduction band for charge collection. This shows that unlike elemental defects and vacancies in $\mathrm{MAPbI}_{3}$, heterovalent dopants likely introduce states within the bandgap of the material. ${ }^{55}$ The incorporation of the dopant must also differ in thin film synthesis compared to single crystal synthesis, as the bandgap shift was 
not observed for similar dopant levels of $\mathrm{Bi}^{3+} .59$

\subsection{Conclusions}

In Sec. 3.1, a broad range of $\mathrm{Bi}^{3+}$ substitutions was reported in thin films of $\mathrm{MAPbI}_{3}$, where it was found that the formation of a mixed phase material was favoured over vacancy formation for intermediate values of $x$. These two phases were found to be $\mathrm{MAPbI}_{3}$ and $\mathrm{MA}_{3} \mathrm{Bi}_{2} \mathrm{I}_{9}$ through XRD measurements. Upon incorporation of these materials into photovoltaic devices, the efficiencies were found to decrease. For the mixed phase materials, the energy levels of the two materials may have prevented efficient transfer of the photogenerated charges to the current collectors. For the $x=1$ material, without any $\mathrm{Pb}^{2+}$ concentration, the low efficiency may have been caused by the wide bandgap or short-circuit pathways between the electron and hole transport materials due to film morphology.

Heterovalent substitution was also studied in the doping regime of $\mathrm{MAPbI}_{3}$ using both $\mathrm{Bi}^{3+}$ and $\mathrm{Tl}^{+}$. The structure of the perovskite was confirmed across all doping levels via XRD analysis and the absorption onset of the materials remained between 1.58 and $1.61 \mathrm{eV}$ for all thin films. It was found that the photovoltaic performance of devices fabricated using these films of the active layer decreased, where the greatest effect was seen upon $\mathrm{Bi}^{3+}$ doping. Contrary to defects in pure $\mathrm{MAPbI}_{3}$ or $\mathrm{Bi}^{3+}$ doping in single crystals, the low current densities of the photovoltaic devices indicated traps states within the bandgap of the material. Due to the formation of a $\mathrm{Tl}^{+}$precipitate in the precursor solution, the final concentration of $\mathrm{Tl}^{+}$in the films is unclear. This may explain why no clear trend is observed in the photovoltaic device parameters as a result of increasing dopant amounts. Further analysis of these films is required to determine the final dopant concentrations, which could be carried out through X-ray Photoelectron Spectroscopy (XPS), however this instrument was not available at the time of writing. 


\section{Pseudo-Halide Substitution in Metal Halide Perovskites}

\subsection{Thiocyanate Substitution in $\mathrm{MAPbBr}_{3}$}

\subsubsection{Motivation}

Recently, incorporation of the thiocyanate ion $\left((\mathrm{SCN})^{-}\right)$into the perovskite structure has been explored. ${ }^{65,66,67,68}$ In 2015, Jiang et al. reported that the material $\mathrm{MAPb}(\mathrm{SCN})_{2} \mathrm{I}$ had been synthesized in the perovskite structure and used as the active layer of a photovoltaic device. ${ }^{65}$ Thin films of this material showed a narrow bandgap of $1.532 \mathrm{eV}$, similar to that observed for $\mathrm{MAPbI}_{3}$, yet with an improved tolerance to humid environments with respect to decomposition. ${ }^{65} \mathrm{Ad}-$ ditionally, devices showed comparable efficiencies with respect to those fabricated using $\mathrm{MAPbI}_{3} .{ }^{65}$ Soon after this, $5 \mathrm{wt} \%(\mathrm{SCN})^{-}$was doped into $\mathrm{MAPbI}_{3}$ in a 2 step method, where again it was claimed that $(\mathrm{SCN})^{-}$had replaced some of the halide ions in the crystal structure. ${ }^{66}$ However, single crystals grown from a solution containing the same stoichiometric amounts of MAI and $\mathrm{Pb}(\mathrm{SCN})_{2}$ used by Jiang et al. were determined to have crystal structures corresponding to $\mathrm{MA}_{2} \mathrm{~Pb}(\mathrm{SCN})_{2} \mathrm{I}_{2} \cdot{ }^{67}$ Further investigation showed absorption characteristics and X-ray diffraction patterns of these crystals agreed with the material reported by Jiang et al., contradicting the claim of $\mathrm{SCN}^{-}$substitution into the halide lattice site of $\mathrm{MAPbI}_{3}{ }^{67}$ These results pertaining to the single crystal study were subsequently challenged when a theoretical study predicted a bandgap of $2.04 \mathrm{eV}$ for $\mathrm{MA}_{2} \mathrm{~Pb}(\mathrm{SCN})_{2} \mathrm{I}_{2} \cdot{ }^{68}$ Qualitatively, this agreed with the red colour displayed by powders and thin films synthesized alongside this theoretical report. ${ }^{68}$ It was determined that the small bandgaps reported in previous studies were likely the result of $\mathrm{MAPbI}_{3}$ impurities in the synthesized material. ${ }^{68}$ Although this discouraged the use of $\mathrm{MA}_{2} \mathrm{~Pb}(\mathrm{SCN})_{2} \mathrm{I}_{2}$ itself as the active layer of a solar cell device, it was found that $\mathrm{Pb}(\mathrm{SCN})_{2}$ as an additive in the synthesis of $\mathrm{MAPbI}_{3}$ thin films resulted 
in a significant increase in grain size and film quality. ${ }^{69}$ No evidence of (SCN) ${ }^{-}$ was found in these films, and so it was proposed that a reaction between $\mathrm{MA}^{+}$ and $(\mathrm{SCN})^{-}$occurred to produce $\mathrm{HSCN}_{(\mathrm{g})}$ and $\mathrm{CH}_{3} \mathrm{NH}_{2(\mathrm{~g})} \cdot{ }^{69}$ The remaining $\mathrm{Pb}_{2}{ }^{+}$ and $\mathrm{I}^{-}$ions reacted to form $\mathrm{PbI}_{2}$, which was found along the grain boundaries in the film. ${ }^{69}$ Low $J-V$ hysteresis measured in these devices was attributed to grain boundary passivation due to this $\mathrm{PbI}_{2} \cdot{ }^{69}$ Here, we investigate the related system of $\mathrm{MAPb}(\mathrm{SCN})_{x} \operatorname{Br}_{(3-x)}$ through synthesis of thin films via a 1 step deposition. $\mathrm{MAPbBr}_{3}$ crystallizes in a cubic unit cell and is a wider bandgap material than $\mathrm{MAPbI}_{3} .{ }^{28}$ The substitution of $\mathrm{Br}^{-}$with $(\mathrm{SCN})^{-}$is attempted by using a stoichiometry of $x \mathrm{~Pb}(\mathrm{SCN})_{2}+(1-x) \mathrm{PbBr}_{2}$, where $\mathrm{x}=0,0.2,0.5$, and 1 , in the precursor solution. A 2 step deposition is tested as well, using subsequent depositions of $\mathrm{Pb}(\mathrm{SCN})_{2}$ and $\mathrm{MABr}$ solutions. Characterization is carried out using XRD, SEM, EDS, UV-Vis absorption and PL studies.

\subsubsection{Method}

Thin Film Deposition: Pre-etched FTO substrates were cleaned in ultrasonic baths of Micron 90 (Sigma Aldrich), deionized water, acetone and isopropanol for 20 minutes per solution. For a 1-step deposition, precursor solutions composed of $1 \mathrm{M}$ MABr (DYESOL) and $1 \mathrm{M} \mathrm{PbX}_{2}\left(x \mathrm{~Pb}(\mathrm{SCN})_{2}\right.$ (Sigma Aldrich, 99.5 $\%)+(1-x) \mathrm{PbBr}_{2}$ (Sigma Aldrich, $\left.\left.99.999 \%\right), \mathrm{x}=0,0.2,0.5,1\right)$ in DMF were used. This solution was deposited under nitrogen via spin-coating at $4000 \mathrm{rpm}$ for $30 \mathrm{~s}$, and annealed at $100{ }^{\circ} \mathrm{C}$ for $30 \mathrm{~min}$. For a 2-step deposition, a $1 \mathrm{M}$ solution of $\mathrm{Pb}(\mathrm{SCN})_{2}$ in DMSO was deposited under nitrogen via spin-coating at $4000 \mathrm{rpm}$ for $40 \mathrm{~s}$. This film was dried at $70{ }^{\circ} \mathrm{C}$ for $10 \mathrm{~min}$. During a $60 \mathrm{~s}$ spin-coating program at $1500 \mathrm{rpm}$, a $20 \mathrm{mg} / \mathrm{mL}$ solution of MABr in isopropanol was dropcast on the substrate for a total of $20 \mathrm{~s}$. The film was annealed at $100{ }^{\circ} \mathrm{C}$ for $30 \mathrm{~min}$. 
Thin Film Characterization: XRD, UV-Vis and SEM measurements were carried out as outlined in section 3.1.2. Photoluminescence was measured on the annealed films under ambient conditions using an excitation wavelength of $400 \mathrm{~nm}$ (HORIBA Jobin Yvon FluoroLog).

\subsubsection{Results and Discussion}

Fig. 4.1 shows XRD patterns of thin films obtained in this study. In the absence of a reference pattern for $\mathrm{MAPbBr}_{3}$, the control sample, $x=0$, can be easily indexed
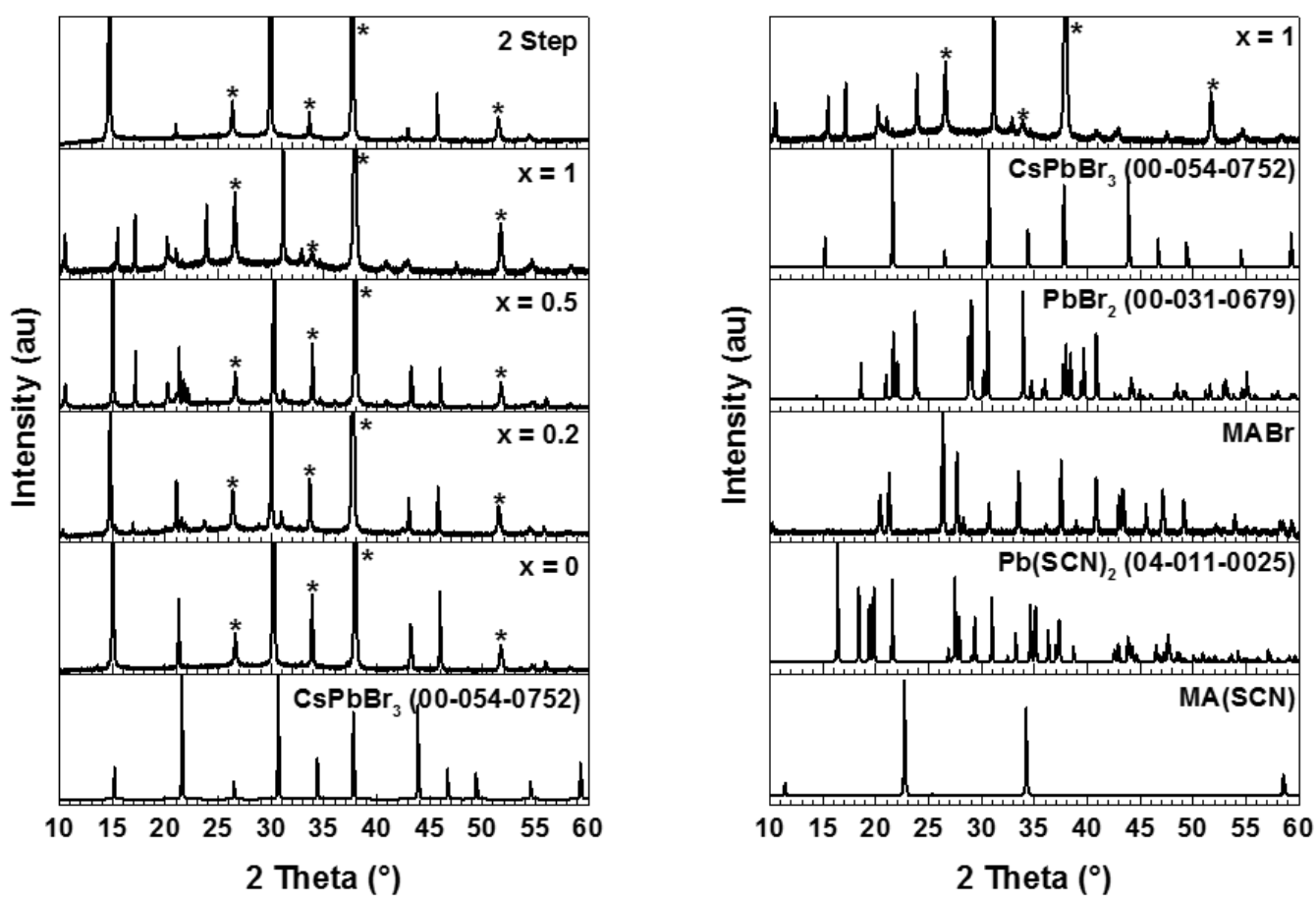

Figure 4.1: (Left) XRD patterns of thin films deposited in 1 step using varying $x \mathrm{~Pb}(\mathrm{SCN})_{2}+(1-x) \mathrm{PbBr}_{2}$ ratios, or 2 steps via $\mathrm{Pb}(\mathrm{SCN})_{2}$, as labelled. $\mathrm{A} \mathrm{CsPbBr}_{3}$ reference is also shown for comparison. (Right) Possible impurity phases compared to the $x=1$ material. Asterisk in all scans denote the FTO substrate. Patterns without a reference number are obtained experimentally. 
to $\mathrm{CsPbBr}_{3}$ (PDF Number 00-054-0752). As the $\mathrm{MA}^{+}$ion is larger than $\mathrm{Cs}^{+}$, it is expected that the peak positions shift to lower values of $2 \theta$, which is confirmed upon analysis of the spectrum. Peaks observed at $2 \theta=15.02664^{\circ}, 21.25764^{\circ}$, $30.21864^{\circ}, 43.19964^{\circ}$ and $45.97164^{\circ}$ can be assigned to the $\langle 100\rangle,\langle 110\rangle,\langle 200\rangle$, $\langle 220\rangle$ and $\langle 300\rangle$ planes of the cubic perovskite lattice, respectively. These peaks are also observed for the $x=0.2$ and 0.5 samples, despite additional impurity peaks appearing. These impurity peaks may be a second phase, or additional lattice planes due to $(\mathrm{SCN})^{-}$incorporation. For a value of $x=1$, however, no perovskite peaks are seen and impurity peaks are prominent at $2 \theta=10.50864^{\circ}$, $15.47364^{\circ}, 17.13264^{\circ}$ and $23.90364^{\circ}$. This pattern is compared to references of possible impurities including $\mathrm{MABr}, \mathrm{MA}(\mathrm{SCN}), \mathrm{PbBr}_{2}$ and $\mathrm{Pb}(\mathrm{SCN})_{2}$ in Fig. 4.1 as well, however the peaks may not be indexed to any of these compounds. To investigate possible reasons behind this unknown impurity, the reaction proposed by Ke et al. is considered. ${ }^{69}$

$$
\begin{aligned}
\mathrm{CH}_{3} \mathrm{NH}_{3} \mathrm{I}+\mathrm{PbI}_{2}+x \mathrm{~Pb}(\mathrm{SCN})_{2} \longrightarrow & (1-2 x) \mathrm{CH}_{3} \mathrm{NH}_{3} \mathrm{PbI}_{3}+3 x \mathrm{PbI}_{2} \\
& +2 x\left(\mathrm{HSCN}_{(\mathrm{g})}+\mathrm{CH}_{3} \mathrm{NH}_{2(\mathrm{~g})}\right)
\end{aligned}
$$

This showed that the $(\mathrm{SCN})^{-}$ions preferentially react with the $\mathrm{MA}^{+}$ions, which decreases the yield of pure $\mathrm{MAPbI}_{3} \cdot{ }^{69}$ Assuming the same reactivity of the (SCN) ${ }^{-}$ ion in the $\mathrm{MAPbBr}_{3}$ system here, the $x=1$ reaction is considered, where no perovskite phase is observed via XRD.

$$
\left(\mathrm{CH}_{3} \mathrm{NH}_{3}\right) \mathrm{Br}+\mathrm{Pb}(\mathrm{SCN})_{2} \longrightarrow \mathrm{HSCN}_{(\mathrm{g})}+\mathrm{CH}_{3} \mathrm{NH}_{2}(\mathrm{~g})+\mathrm{Pb}(\mathrm{SCN}) \mathrm{Br}
$$

If the $(\mathrm{SCN})^{-}$ions are not incorporated into the structure, the limiting factor to perovskite formation here is the lack of sufficient $\mathrm{Br}^{-}$ions in solution. Also, there are insufficient $\mathrm{MA}^{+}$ions in solution to interact with all of the $(\mathrm{SCN})^{-}$ions 

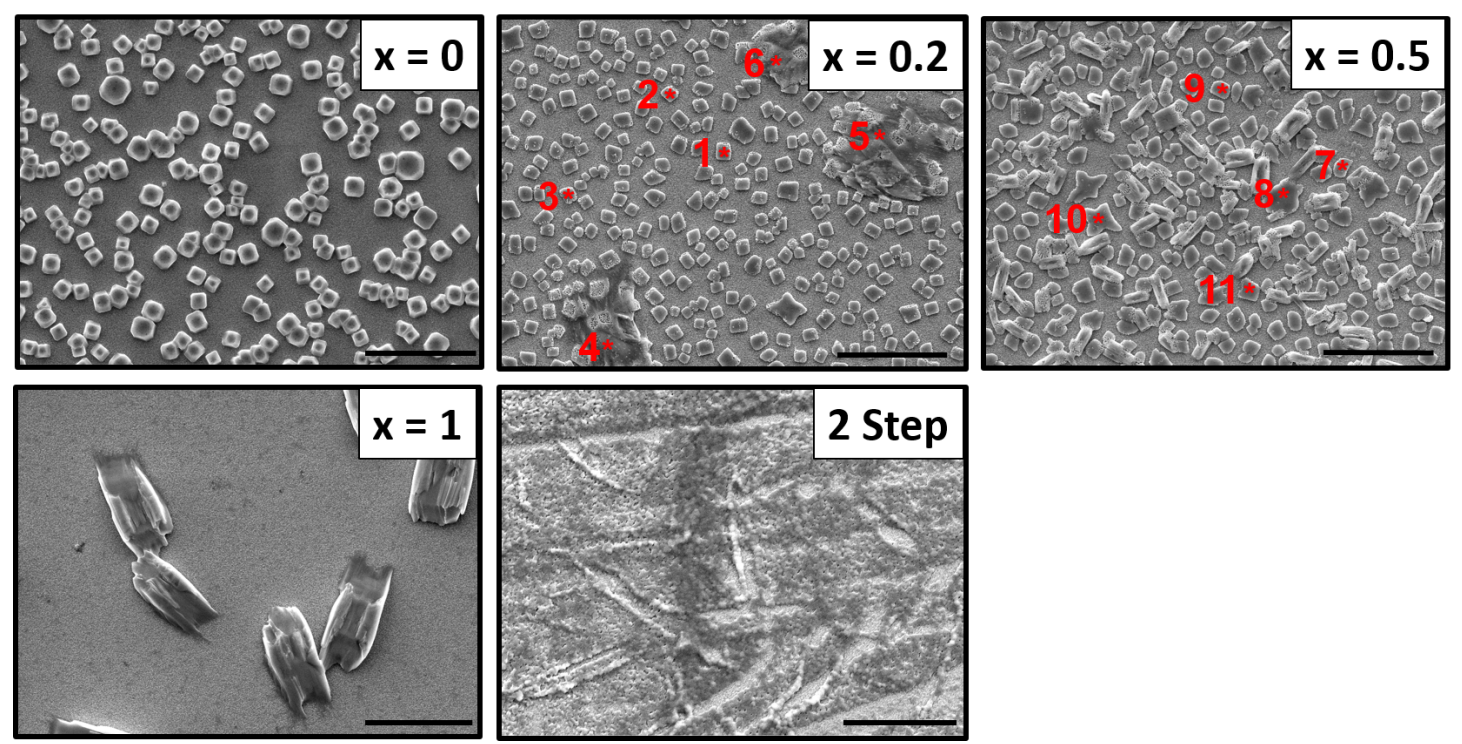

Figure 4.2: SEM images of thin films deposited in 1 step using varying $x \mathrm{~Pb}(\mathrm{SCN})_{2}+(1-x) \mathrm{PbBr}_{2}$ ratios, or 2 steps via $\mathrm{Pb}(\mathrm{SCN})_{2}$, as labelled. The scale bars represent $20 \mu \mathrm{m}$ in each image. Asterisk denote EDS point scans, the results of which are tabulated.

in a decomposition reaction. The remaining atomic ratios of ions solution have a stoichiometry corresponding to a $\mathrm{Pb}(\mathrm{SCN}) \mathrm{Br}$ salt. Now considering the $x=$ 0.5 reaction, there are sufficient $\mathrm{MA}^{+}$ions to react with all $\mathrm{SCN}^{-}$ions, yet the perovskite phase is still present via XRD. This indicates that not all of the $\mathrm{MA}^{+}$ ions react to form a gas for this composition and therefore competing reactions exist between $\mathrm{MAPbBr}_{3}$ formation and decomposition of $\mathrm{MA}^{+}$via $(\mathrm{SCN})^{-}$. In the XRD pattern for the 2 step deposition, a pure perovskite pattern is regained. Now, if incorporation of $(\mathrm{SCN})^{-}$was assumed in the 1 step depositions, this 2 step deposition would likely have the same impurity peaks seen in the $x=0.2,0.5$ and 1 patterns. However no impurity peaks are present, which implies that in the second deposition step, sufficient MABr was deposited on the films to first react with all the $(\mathrm{SCN})^{-}$, and subsequently form $\mathrm{MAPbBr}_{3}$.

The morphology of the thin films is observed via SEM and the resulting images 


\begin{tabular}{|c|c|c|c|c|}
\hline Area & $\mathrm{Pb}$ (atomic \%) & $\mathrm{Br}$ (atomic \%) & $\mathrm{S}$ (atomic \%) & $\mathrm{Pb}: \mathrm{Br}$ \\
\hline \hline $\mathbf{x = 0}$ & $\mathbf{2 . 7 8}$ & $\mathbf{8 . 2 3}$ & $\mathbf{0}$ & $\mathbf{1 : 2 . 9 6}$ \\
\hline $\mathbf{X}=\mathbf{0 . 2}$ & $\mathbf{2 . 2 9}$ & $\mathbf{5 . 2 6}$ & $\mathbf{0 . 4 4}$ & $\mathbf{1 : 2 . 3 0}$ \\
1 & 3.96 & 12.19 & 0 & $1: 3.08$ \\
2 & 4.17 & 12.33 & 0.17 & $1: 2.96$ \\
3 & 4.71 & 13.13 & 0 & $1: 2.79$ \\
4 & 13.07 & 12.48 & 5.24 & $1: 0.96$ \\
5 & 8.99 & 8.46 & 4.31 & $1: 0.94$ \\
6 & 13.64 & 11.16 & 6.65 & $1: 0.82$ \\
\hline $\mathbf{X . 5}$ & $\mathbf{4 . 4 6}$ & $\mathbf{8 . 6 9}$ & $\mathbf{0 . 9 7}$ & $\mathbf{1 : 1 . 9 5}$ \\
7 & 5.06 & 14.44 & 0 & $1: 2.85$ \\
8 & 5.63 & 18.60 & 0 & $1: 3.30$ \\
9 & 5.08 & 14.24 & 0 & $1: 2.80$ \\
10 & 6.76 & 20.13 & 0 & $1: 2.98$ \\
\hline $\mathbf{x}=\mathbf{1}$ & $\mathbf{2 . 0 6}$ & $\mathbf{1 . 9 0}$ & $\mathbf{0 . 8 2}$ & $\mathbf{1 : 0 . 9 2}$ \\
\hline 2 Step & $\mathbf{2 . 6 8}$ & $\mathbf{9 . 3 7}$ & $\mathbf{0}$ & $\mathbf{1 : 3 . 5 0}$ \\
\hline
\end{tabular}

Table 4.1: EDS Data corresponding to Fig. 4.2. Results of an area scan of an entire image are in bold. Point scans are numbered corresponding to labels in Fig. 4.2.

are shown in Fig. 4.2. Cubic crystals are observed for the $x=0$ composition and EDS analysis of the entire area shows a $\mathrm{Pb}: \mathrm{Br}$ atomic ratio of 1:2.96, in agreement with the $\mathrm{MAPbBr}_{3}$ stoichiometry. As $x$ is increased to 0.2 and 0.5 , cubic particles continue to be present in the films, however crystals of different morphology are observed in addition to these. For these films, EDS analysis was performed both on the entire area of the image shown in Fig. 4.2, as well as on defined spots within the image, as labelled. The results of these scans are compiled in Table 4.1. Analysis of the $x=0.2$ film shows that the cubic crystals scanned at spots 1,2 and 3 continue to have $\mathrm{Pb}: \mathrm{Br}$ atomic ratios of approximately 1:3, with very little, if any, S present. This is again consistent with the $\mathrm{MAPbBr}_{3}$ structure. Spots 4, 5 and 6 result in $\mathrm{Pb}: \mathrm{Br}$ ratios of roughly 1:1, with a significant increase of $\mathrm{S}$ as well. Here it should be noted that the signals due to $\mathrm{Pb}$ and $\mathrm{S}$ in the EDS spectra overlap to some extent, and therefore the values here may have error associated 


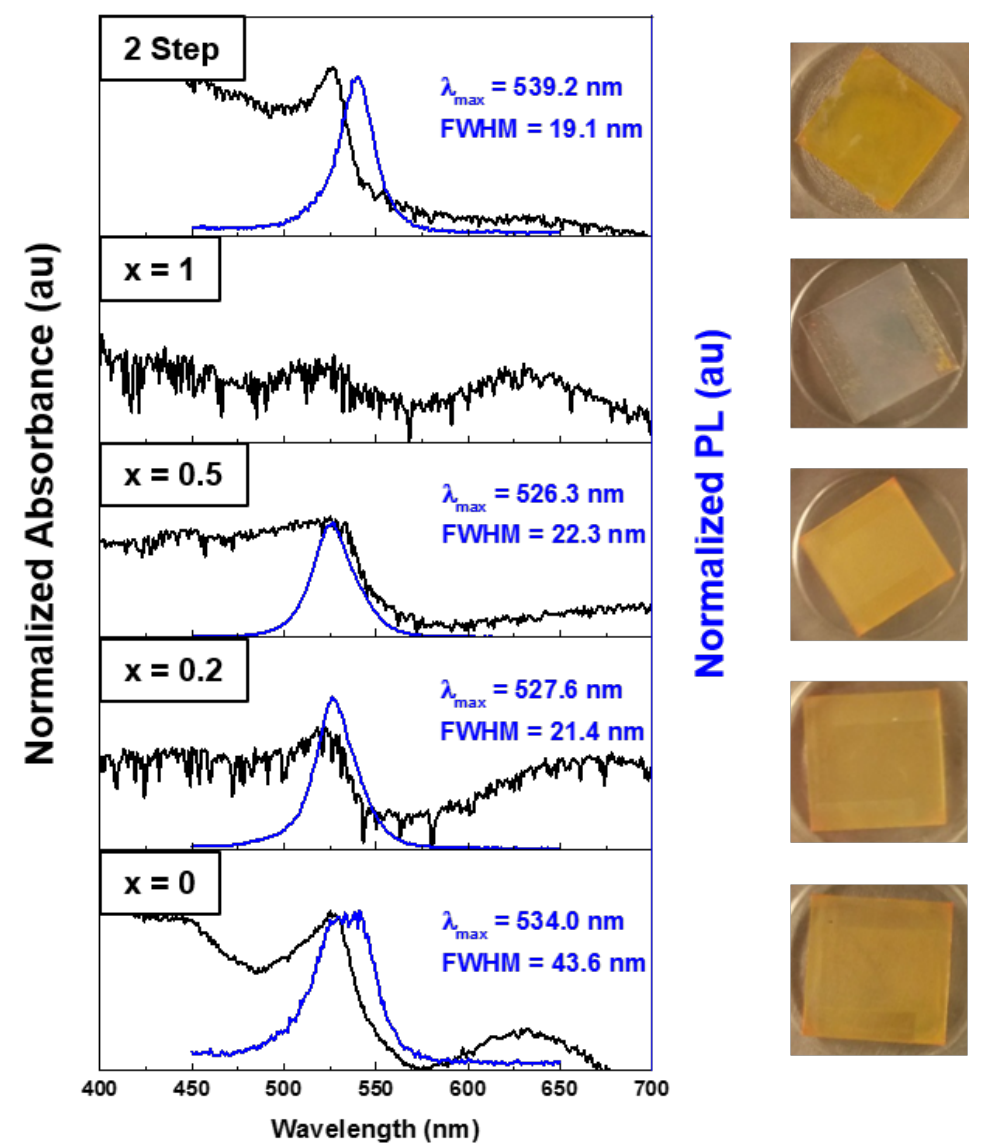

Figure 4.3: UV-Vis absorption, PL spectra and optical images of thin films deposited in 1 step using varying $x \mathrm{PbBr}_{2}+(1-x) \mathrm{Pb}(\mathrm{SCN})_{2}$ ratios, or 2 steps via $\mathrm{Pb}(\mathrm{SCN})_{2}$, as labelled.

with them. However there appears to be significance within these measurements, as differentiation between various crystal morphologies correspond to variations in the reported $\mathrm{S}$ content. All spot scans for the $x=0.5$ film roughly correspond to the $\mathrm{MAPbBr}_{3}$ stoichiometry. This would contradict XRD analysis, however the atomic ratio of $\mathrm{Pb}: \mathrm{Br}$ over the entire image is 1:1.95. Likely the selection of spot scans included only perovskite phase crystals, despite different crystal morphologies being chosen. This indicates a variation in perovskite morphology upon changing the reaction conditions. The $x=1$ film shows a change in crystal 
morphology and size when compared to all other compositions. EDS analysis shows a $\mathrm{Pb}: \mathrm{Br}$ atomic ratio of 1:0.92, consistent with the proposed $\mathrm{Pb}(\mathrm{SCN}) \mathrm{Br}$ structure. The inconsistency of the $\mathrm{S}$ signal here, as shown in Table 4.1 may be due to the overlapping $\mathrm{Pb}$ and $\mathrm{S}$ signals. Again, for the film made using the 2 step deposition process, the $\mathrm{MAPbBr}_{3}$ phase appears to be present, with a $\mathrm{Pb}: \mathrm{Br}$ atomic ratio of 1:3.50, without any report of $\mathrm{S}$.

Finally, optical absorption and emission spectra of the films are shown in Fig. 4.3. A large degree of scattering in the absorption spectra, shown in black, prevents a detailed analysis of these films. However, a consistent absorption edge appears at approximately $550 \mathrm{~nm}$ for the $x=0,0.2$ and 0.5 films. In previous reports, a similar bandgap was reported for $\mathrm{MAPbI}_{3}$ and $\mathrm{MAPb}(\mathrm{SCN})_{2} \mathrm{I}$, which corresponds

to the $x=1$ composition in this experiment. ${ }^{65}$ However here, the absorption edge is lost for $x=1$. Comparing this to corresponding images of the films, also shown in Fig. 4.3, this is not surprising as very little yellow appears in the film. PL spectra of the films are more successful with respect to scattering, and emission is obtained for all film compositions except $x=1$. Upon fitting these emission peaks to a Gaussian function, the wavelength of maximum intensity shifts to higher energies for the $x=0.2$ and 0.5 films. If this indicated $\mathrm{SCN}^{-}$substitution into the perovskite structure, one would expect this trend to continue for the $x=1$ film. However no PL is observed for this film. Additionally, the wavelength of maximum PL intensity for the film deposited in 2 steps, where there is sufficient $(\mathrm{SCN})^{-}$available for incorporation if possible, does not show this shift.

\subsection{Conclusions}

Incorporation of the $(\mathrm{SCN}-)$ ion into the $\mathrm{MAPbB}_{3}$ structure was investigated here and compared to similar investigations of the $\mathrm{MAPb}(\mathrm{SCN})_{x} \mathrm{I}_{3-x}$ system. Structural changes in the XRD patterns were likely the result of impurities, upon comparison 
with corresponding UV-Vis, PL and SEM analyses. It appears that the reactivity of the $\mathrm{MA}^{+}$ion with $(\mathrm{SCN})^{-}$prevents the formation of a pure perovskite phase for compositions of $x=0.2,0.5$ and 1 . Confirmation of this reactivity may be achieved through XPS measurements, whereby a direct comparison may be made between the initial $\mathrm{S}$ concentration in the precursor solution, and the final concentration in the thin film. Also, investigations of the inorganic system $\mathrm{CsPb}(\mathrm{SCN})_{x} \mathrm{Br}_{3-x}$ would eliminate this possibility of this decomposition reaction. 


\section{Properties of $\mathrm{Cs}_{3} \mathrm{Bi}_{2} \mathrm{X}_{9}$ Nanocrystals}

\section{$5.1 \quad \mathrm{Cs}_{3} \mathrm{Bi}_{2} \mathrm{I}_{9}$ Nanocrystals}

\subsubsection{Motivation}

As described in section 1.5.2, there have been multiple reports on the properties of lead halide nanocrystals such as bandgap tunability, quantum confinement and high PLQE values. ${ }^{42,44,43,45}$ Following the trend seen with single crystals and thin films of these perovskites, non-toxic replacements for $\mathrm{Pb}^{2+}$ in the nanocrystals have also been explored. ${ }^{70,71}$ Synthesis and characterization of $\operatorname{CsSnX}_{3}\left(\mathrm{X}=\mathrm{I}, \mathrm{Br}_{1.5} \mathrm{I}_{1.5}\right.$, $\left.\mathrm{Br}, \mathrm{Cl}_{1.5} \mathrm{Br}_{1.5}, \mathrm{Cl}\right)$ nanocrystals revealed compositional and quantum size effects on optical properties, analogous to the $\mathrm{CsPbX}_{3}$ nanocrystals. ${ }^{42,70}$ Using these effects the bandgap was tuned between 1.3 and $2.8 \mathrm{eV}$ for the $\mathrm{CsSnX}_{3}$ particles. ${ }^{70}$ Across the range of compositions synthesized, a maximum PLQE of $0.14 \%$ was observed for the $\mathrm{CsPbBr}_{3}$ nanocrystals ${ }^{70}$ This was relatively low compared to the PLQE values of $50-90 \%$ seen for $\mathrm{CsPbX}_{3}$ particles. ${ }^{42}$ In an effort to synthesize other leadfree luminescent nanocrystals, this project is motivated by a paper which studied the properties of $\mathrm{MA}_{2} \mathrm{Bi}_{3} \mathrm{I}_{9}, \mathrm{Cs}_{3} \mathrm{Bi}_{2} \mathrm{I}_{9}$ and $\mathrm{MA}_{3} \mathrm{Bi}_{2} \mathrm{I}_{9} \mathrm{Cl}_{x}$ thin films. ${ }^{48}$ Out of these materials, the only film that showed emission was $\mathrm{Cs}_{3} \mathrm{Bi}_{2} \mathrm{I}_{9}$, which had an optical bandgap of $2.2 \mathrm{eV}$. Therefore, nanocrystals of the same composition may also prove to be luminescent in the visible region and possibly compete with the high PLQE values seen for $\mathrm{CsPbX}_{3}$ nanocrystals. Recently, $\mathrm{MA}_{3} \mathrm{Bi}_{2} \mathrm{X}_{9}$ nanocrystals were also synthesized, and a PLQE of $14 \%$ was observed for the composition $\mathrm{MA}_{3} \mathrm{Bi}_{2} \mathrm{Br}_{9} \cdot{ }^{71}$ As with the lead and tin based particles, these showed compositional tunability and postsynthetic anion exchange. ${ }^{42,44,70,71}$ This report increased the motivation to synthesize the related family of $\mathrm{Cs}_{3} \mathrm{Bi}_{2} \mathrm{X}_{9}$ nanocrystals, as this study confirmed the possibility of synthesizing perovskite nanocrystals lacking the $3 \mathrm{D}$ connectivity of the $\mathrm{ABX}_{3}$ structure. ${ }^{71}$ Synthesis of these particles is explored through the hot 
injection method and studied through XRD, UV-Vis, TEM and STEM studies.

\subsubsection{Methods}

Cs-Oleate Synthesis: $2.50 \mathrm{mmol} \mathrm{Cs}_{2} \mathrm{CO}_{3}$ (99\%, Sigma Aldrich), $40 \mathrm{~mL}$ 1-octadecene (ODE) (technical grade, 90\%, Sigma Aldrich) and $2.5 \mathrm{~mL}$ oleic acid (OA) (technical grade, 90\%, Sigma Aldrich) were added to a round bottom flask. The solution was placed under vacuum for $1 \mathrm{~h}$ at $120^{\circ} \mathrm{C}$. Under nitrogen, the solution was heated to $150{ }^{\circ} \mathrm{C}$ for $1 \mathrm{hr}$. The product was stored under nitrogen.

Nanocrystal Synthesis: $0.375 \mathrm{mmol} \mathrm{BiX}_{3}\left(x\left(\mathrm{BiBr}_{3}, 98+\%\right.\right.$, Strem Chemicals $)+(1-$ $x)\left(\mathrm{BiI}_{3}, 99.999 \%\right.$, Strem Chemicals $\left.)\right)$ and $10 \mathrm{~mL}$ ODE were added to a round bottom flask and heated to $120{ }^{\circ} \mathrm{C}$ under vacuum for $1 \mathrm{hr}$. In a separate vial, a 1:1 v/v mixture of oleylamine (OLA) ( $\geq 98 \%$, Sigma Aldrich) and OA was placed under vacuum at room temperature for $1 \mathrm{hr} .2 \mathrm{~mL}$ of the 1:1 v/v OLA:OA solution was added to the round bottom flask at $120{ }^{\circ} \mathrm{C}$ under nitrogen. The temperature of the flask was increased to $180{ }^{\circ} \mathrm{C} .0 .8 \mathrm{~mL}$ of hot $0.125 \mathrm{M}$ Cs-oleate solution was quickly injected into the reaction flask. The reaction was allowed to stir for $10 \mathrm{~s}$ at $180^{\circ} \mathrm{C}$, then cooled to room temperature with a water bath. The growth solution was centrifuged at $1000 \mathrm{rpm}$ for $6 \mathrm{~min}$ to remove large impurities. The particles in the resulting supernatant were collected by centrifuging the solution twice, without anti-solvent at 10,000 rpm for $8 \mathrm{~min}$. Particles were re-dispersed in anhydrous hexane.

Nanocrystal Analysis: The structure of the nanocrystals was analyzed via XRD and TEM (JEOL 2100F and JEOL 2010). Optical properties of the nanocrystals were studied via UV-Vis spectroscopy (Varian Cary 50 Spectrophotometer) of the growth solutions diluted in hexane. 


\subsubsection{Results and Discussion}

The XRD pattern of the iodide nanocrystals, $x=0$, is shown in Fig. 5.1. Reference patterns of the starting material, $\mathrm{BiI}_{3}$, and the expected product, $\mathrm{Cs}_{3} \mathrm{Bi}_{2} \mathrm{I}_{9}$, are also shown. In determining whether there is any residual $\mathrm{BiI}_{3}$ precursor left over, the $\mathrm{BiI}_{3}$ peak near $2 \theta=27^{\circ}$ is used, as the $\mathrm{Cs}_{3} \mathrm{Bi}_{2} \mathrm{I}_{9}$ pattern is not expected to have significant intensity in this region. The experimental data does not show a peak from $35-36^{\circ}$ and so based on this $\mathrm{XRD}$ pattern, no residual $\mathrm{BiI}_{3}$ is present in the product. The XRD data also indicates that the expected $\mathrm{Cs}_{3} \mathrm{Bi}_{2} \mathrm{I}_{9}$ structure is present. This perovskite phase is characterized in part by intense peaks occurring at $2 \theta=12.8378^{\circ}, 25.8023^{\circ}, 27.5065^{\circ}$, and $29.9602^{\circ}$ which correspond to the $\langle 101\rangle$,

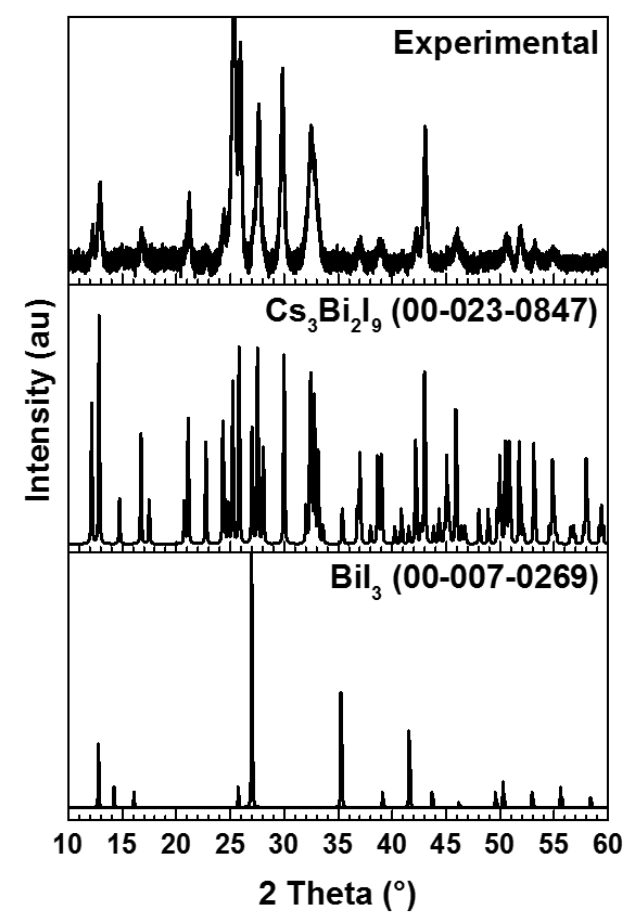

Figure 5.1: XRD patterns showing experimental data obtained from hot injection synthesis of $\mathrm{Cs}_{3} \mathrm{Bi}_{2} \mathrm{I}_{9}$ nanocrystals. Also shown are reference patterns for $\mathrm{Cs}_{3} \mathrm{Bi}_{2} \mathrm{I}_{9}$ and $\mathrm{BiI}_{3}$. 

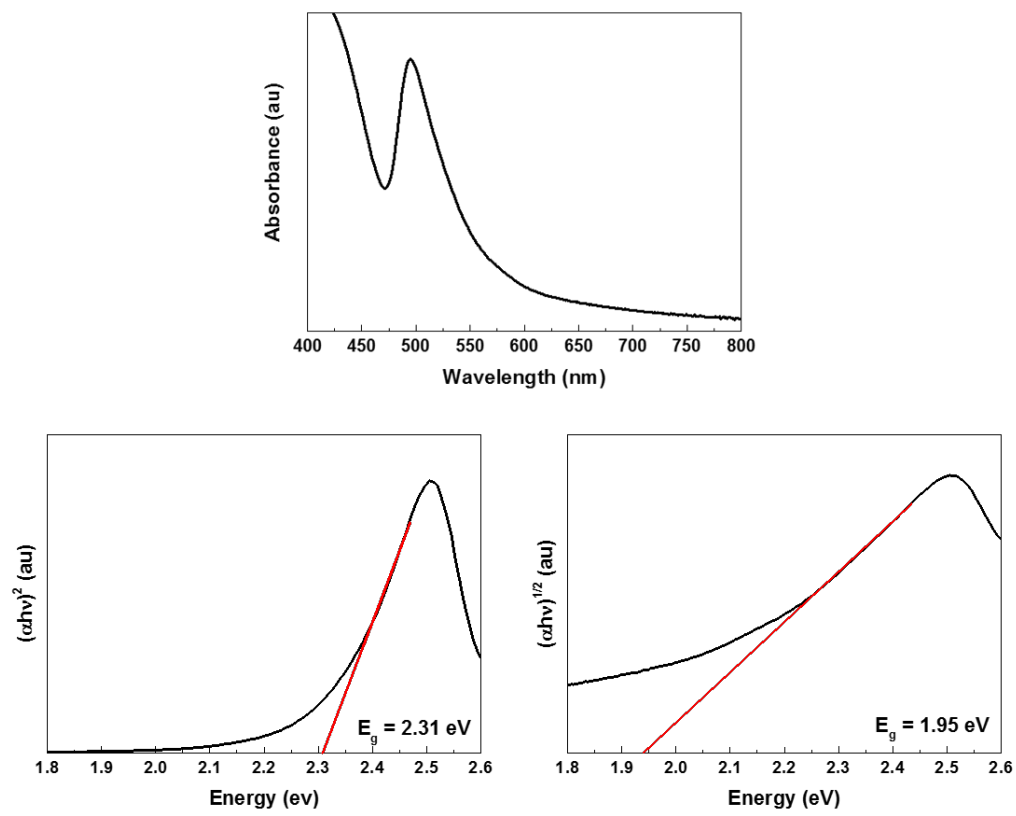

Figure 5.2: (Top) UV-Vis absorption spectrum of $\mathrm{Cs}_{3} \mathrm{Bi}_{2} \mathrm{I}_{9}$ Nanocrystals. (Bottom) Tauc plots for the direct (left) and indirect (right) bandgaps of the $\mathrm{Cs}_{3} \mathrm{Bi}_{2} \mathrm{I}_{9}$ nanocrystals.

$\langle 202\rangle,\langle 203\rangle$ and $\langle 204\rangle$ planes of the $\mathrm{Cs}_{3} \mathrm{Bi}_{2} \mathrm{I}_{9}$ lattice, respectively (PDF Number 00-023-0847). Although the resolution of the experimental data is low, peaks corresponding to these planes are present in the experimental data. The broad peaks could be a result of the many discrete peaks occurring within small ranges of $2 \theta$, visible in the reference pattern, or the size of the nanocrystals. Broad signals obtained in nanocrystal synthesis have been reported previously and attributed to the small size of the particles. ${ }^{43,70}$

The UV-Vis spectra of the growth solution is shown in Fig. 5.2. This absorption data was used to create Tauc plots corresponding to both a direct and indirect bandgap, also shown in Fig. 5.2. The bandgaps obtained through extrapolation of this data to the $\mathrm{x}$-axis are $2.31 \mathrm{eV}$ and $1.95 \mathrm{eV}$ for a direct and indirect bandgap, respectively, where a sharper edge is observed for the direct gap. $\mathrm{Cs}_{3} \mathrm{Bi}_{2} \mathrm{I}_{9}$ has 

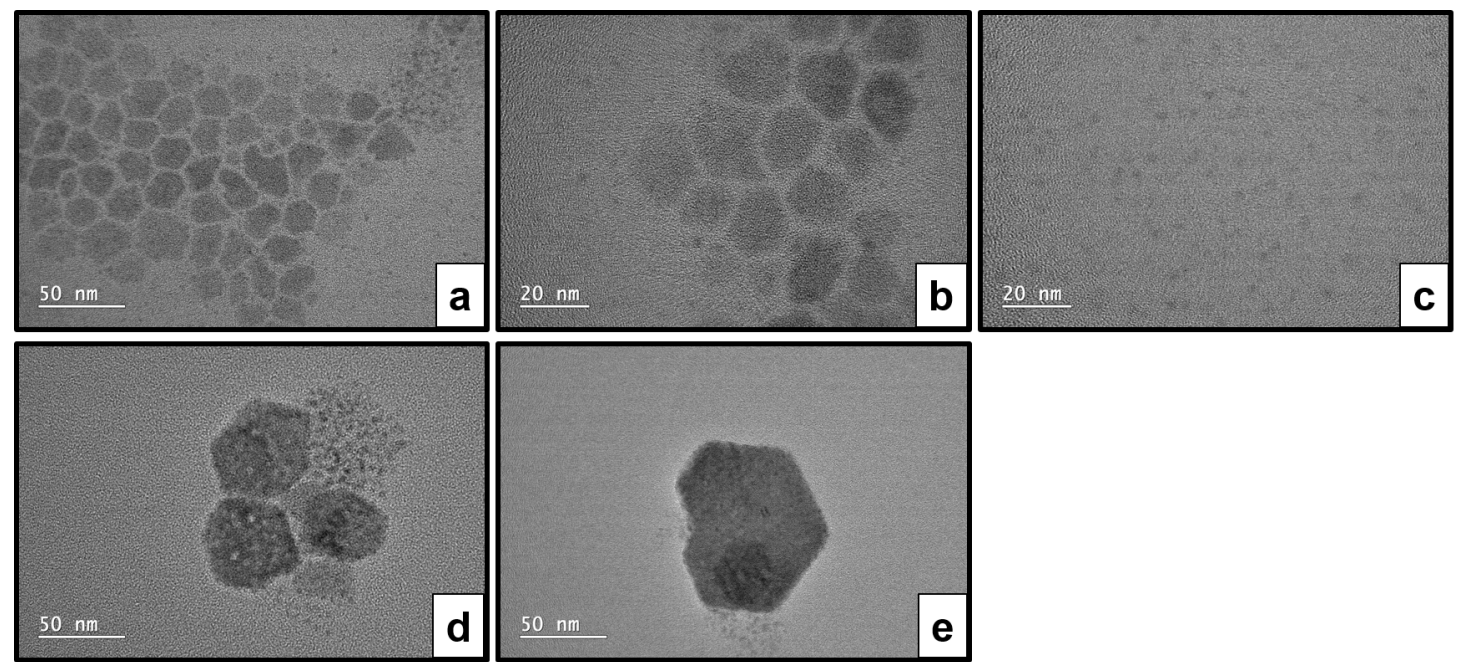

Figure 5.3: TEM images of the $\mathrm{Cs}_{3} \mathrm{Bi}_{2} \mathrm{I}_{9}$ nanocrystal hot injection synthesis.

been determined to have an indirect bandgap of $2.3 \mathrm{eV}$ theoretically, whereas experimentally it was found to be $1.9 \mathrm{eV} .{ }^{58}$. Given this range, the results of the Tauc plots are do not rule out a $\mathrm{Cs}_{3} \mathrm{Bi}_{2} \mathrm{I}_{9}$ phase.

TEM images of these particles are shown in Fig. 5.3, and the EDS data corresponding to these images is tabulated in Table 5.1. Particles with diameters between approximately 20 and $50 \mathrm{~nm}$ are present, and for some of these, a hexagonal symmetry is clearly present. As $\mathrm{Cs}_{3} \mathrm{Bi}_{2} \mathrm{I}_{9}$ crystallizes in a hexagonal unit cell, these crystals may be the $\mathrm{Cs}_{3} \mathrm{Bi}_{2} \mathrm{I}_{9}$ product. There are also smaller particles present in all the images, and specifically imaged in Fig. 5.3 c. To determine if

\begin{tabular}{|c|c|c|c|c|}
\hline Image & Cs (atomic \%) & Bi (atomic \%) & I (atomic \%) & Cs:Bi:I \\
\hline \hline $\mathrm{a}$ & 0.01 & 0.04 & 0.04 & $1.00: 4.00: 4.00$ \\
$\mathrm{~b}$ & 0.05 & 0.07 & 0.19 & $1.00: 1.40: 3.80$ \\
$\mathrm{c}$ & 0 & 0.09 & 0.06 & $\mathrm{n} / \mathrm{a}$ \\
$\mathrm{d}$ & 0.02 & 0.02 & 0.06 & $1.00: 1.00: 3.00$ \\
$\mathrm{e}$ & 0.02 & 0.02 & 0.05 & $1.00: 1.00: 2.50$ \\
\hline
\end{tabular}

Table 5.1: EDS Data corresponding to the TEM images shown in Fig. 5.3. 


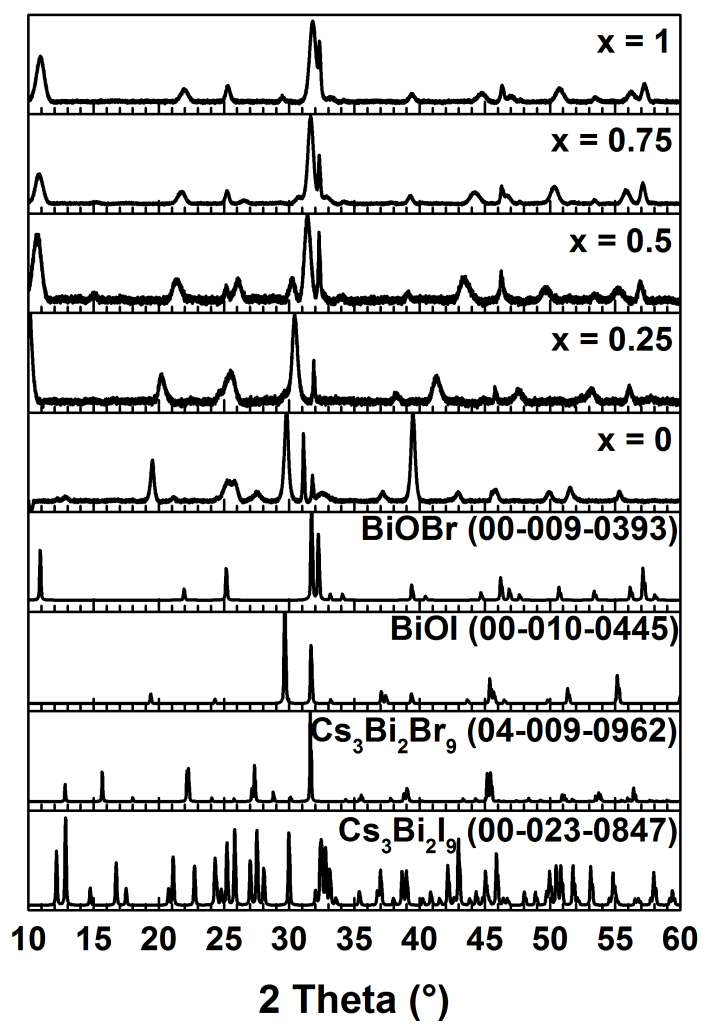

Figure 5.4: XRD patterns for a range of halide compositions. $x$ denotes the ratio of $\mathrm{Br}^{-}$substitution: $x \mathrm{BiBr}_{3}+(1-x) \mathrm{BiI}_{3}$, as labelled. Reference patterns of the expected products and possible impurity products are shown in the bottom four panels.

there is any compositional difference in the particles of different size, EDS data of these particles was obtained as well and is shown in Table 5.1. The atomic percentages of the elements of interest are low, where the remainder of the signal for all scans is due to $\mathrm{C}, \mathrm{N}, \mathrm{O}$ and $\mathrm{Cu}$. While the $\mathrm{C}$ and $\mathrm{Cu}$ are elements of the sample substrate necessary for imaging, $\mathrm{N}$ and $\mathrm{O}$ are attributed to environmental contamination. All images showing the larger particles (a, b, d, e) confirm the presence of $\mathrm{Cs}, \mathrm{Bi}$ and $\mathrm{I}$. The ideal atomic ratio of $\mathrm{Cs}$ : I for $\mathrm{Cs}_{3} \mathrm{Bi}_{2} \mathrm{I}_{9}$ is 1:3, and 
the experimental atomic ratios from EDS are 1.00:4.00, 1.00:3.80, 1.00:3.00 and 1.00:2.50 for images a, c, d and e, respectively. This indicates that these particles are likely the $\mathrm{Cs}_{3} \mathrm{Bi}_{2} \mathrm{I}_{9}$ structure observed with XRD. Elemental analysis through EDS for Fig. 5.3 c shows no Cs in the area scanned, while Bi and I continue to be present. This indicates an impurity that was not obvious through XRD analysis. Due to the small size of the particles, the majority of the XRD signal is likely due to the larger particles seen in Fig. 5.3 a, b, d, and e. The Bi:I ratio for scans of the large particles vary significantly from the ideal 1:4.5 ratio of a stoichiometric $\mathrm{Cs}_{3} \mathrm{Bi}_{2} \mathrm{I}_{9}$ structure, however the small impurity particles, where $\mathrm{Bi}$ is the majority of the atomic composition, are also present in the scan area. This may be a factor affecting the elemental analysis of the nanocrystals. As prolonged imaging time causes these particles to degrade, STEM imaging could not be used to separate atomic signals between the large and small particles.

As the synthesis of $\mathrm{Cs}_{3} \mathrm{Bi}_{2} \mathrm{I}_{9}$ nanocrystals was successful, this project also investigated the mixed halide system between I and Br. Fig. 5.4 shows XRD spectra of particles synthesized through the hot injection synthesis for compositions of $x=$ $0,0.25,0.5,0.75$ and 1 at a later date. Here, a large difference is seen between the $x=0$ pattern in Fig. 5.4 compared to the pattern in Fig. 5.1, although these scans represent particles synthesized under the same reaction conditions. Some of the peaks in this new scan may still be attributed to the perovskite peaks discussed earlier. However, with the exception of one unknown peak at $2 \theta=31.78464^{\circ}$, the impurity peaks can be attributed to the BiOI phase (PDF Number 00-010-0445). As the concentration of $\mathrm{BiBr}_{3}$ in the precursor solution is increased, the impurity peaks increase in intensity with respect to the perovskite peaks. For the $x=1$ synthesis, the perovskite peaks disappear completely, and all but one minor peak may be indexed to the BiOBr crystal structure (PDF Number (00-009-0393). A reference pattern for the desired $\mathrm{Cs}_{3} \mathrm{Bi}_{2} \mathrm{Br}_{9}$ product is also given. 

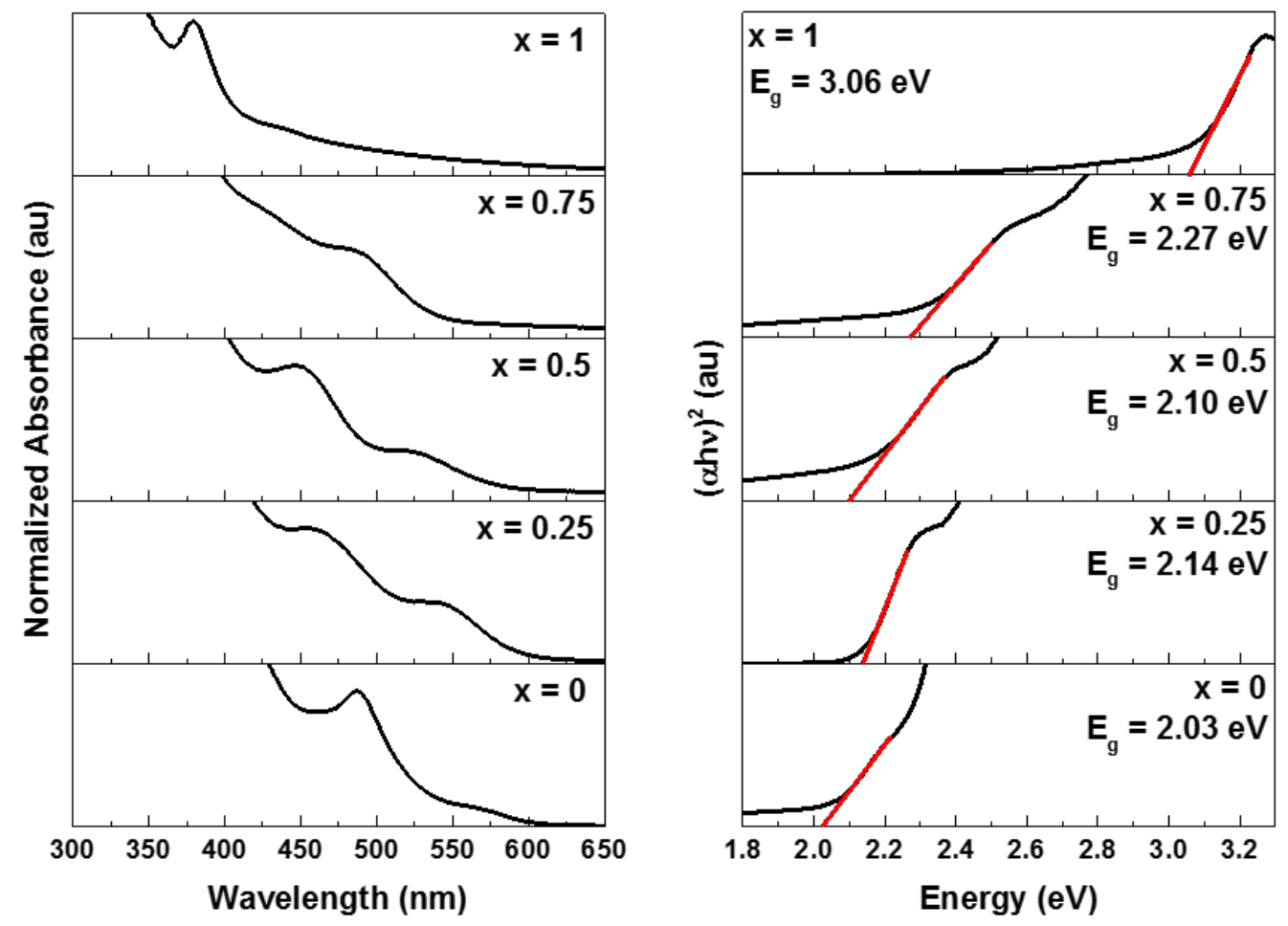

Figure 5.5: (Left) UV-Vis absorption spectra of the growth solutions for the mixed halide hot injection synthesis. (Right) Corresponding Tauc plots, assuming a direct bandgap.

The UV-Vis absorption spectra of the range of growth solutions are shown in Fig. 5.5. Here again, the corresponding Tauc plots assuming a direct bandgap showed a sharper edge compared to a indirect bandgap. The results are also shown in Fig. 5.5. A shift of $0.27 \mathrm{eV}$ occurred for the $x=0$ reaction, compared to the previously synthesized particles of the same composition. Here, the experimental bandgaps are compared to those of the impurities found through XRD, which are 1.906 and $2.865 \mathrm{eV}$ for $\mathrm{BiOI}$ and $\mathrm{BiOBr}$, respectively. ${ }^{72}$ This data does not conclusively confirm either the desired perovskite structure, or the impurity. However a clear shift from the previous synthesis indicates an unintentional change in reaction conditions. Also, this absorption data may be due to a summation of 

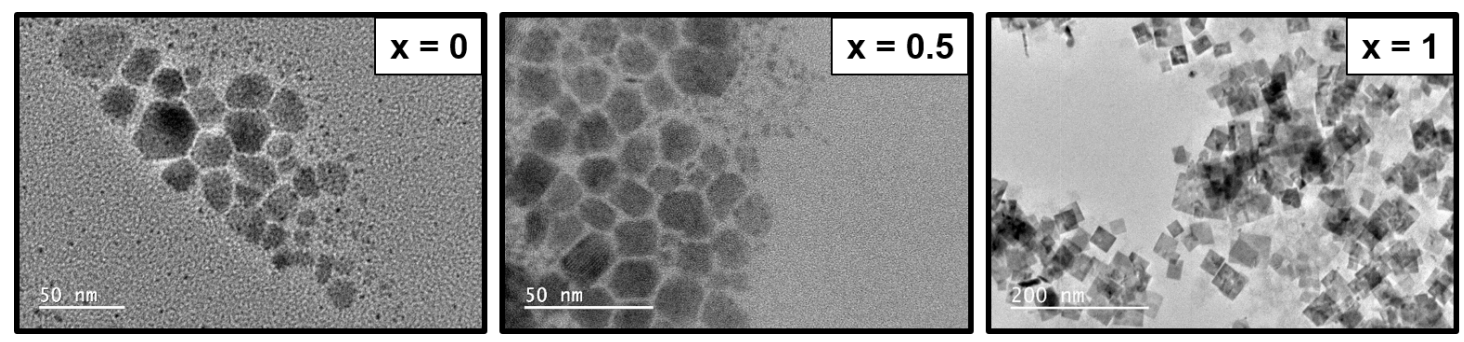

Figure 5.6: TEM images of mixed halide nanocrystal syntheses corresponding to $x=0,0.5$ and 1 , as labelled.

the products in the solution.

TEM images of the products for the $x=0,0.5$ and 1 reactions are shown in Fig. 5.6. Similar crystal size and morphology are seen for the $x=0$ and $0.5 \mathrm{im}-$ ages, compared to the particles shown in Fig. 5.3. The $x=1$ particles however, show a morphology change to well defined cubes. STEM analysis was able to be carried out on the $x=1$ particles, and is shown in Fig. 5.7. The particles chosen for analysis via STEM mapping were Bi, I, Cs and Br. Overall the Bi:Br atomic ratio of these particles is 1.00:1.70, which does not confirm the proposed $\mathrm{BiOBr}$
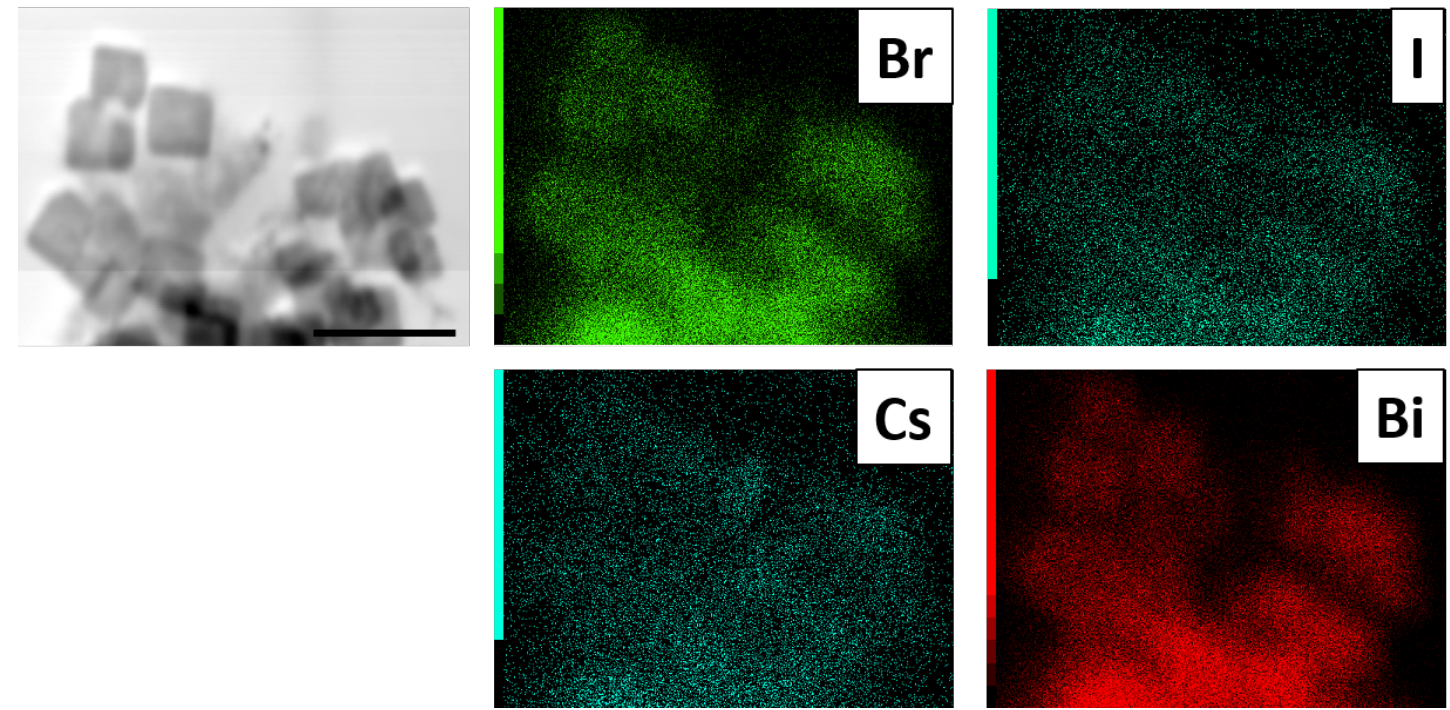

Figure 5.7: STEM analysis and corresponding element maps of the $x=1$ nanocrystals synthesis. The scale bar represents $200 \mathrm{~nm}$. 
impurity. However this also shows that this ratio does not agree with the desired perovskite structure as well. Additionally, the atomic ratios of Br:Cs and Br:I are both 0.02 . Since I was not part of this reaction, the Cs signal may be attributed to noise. The STEM maps of $\mathrm{Br}$ and $\mathrm{Bi}$ show that these elements exist in the same crystals within the sample.

\subsection{Conclusions}

This experiment investigated the synthesis of $\mathrm{Cs}_{3} \mathrm{Bi}_{2} \mathrm{X}_{9}$ nanocrystals through the hot injection method. The successful synthesis of $\mathrm{Cs}_{3} \mathrm{Bi}_{2} \mathrm{I}_{9}$ nanocrystals is supported through XRD, UV-Vis, TEM and EDS analysis. After this determination, subsequent reactions were carried out in an attempt to synthesis mixed halide particles as well. However these reactions showed a large concentration of impurity in the XRD patterns of all synthesized particles. It is believed that these impurities correspond to a $\mathrm{BiOX}$ phase. As this phase is present throughout the range of halide compositions tested, including the pure iodide synthesis, an unintentional oxygen impurity was likely introduced to the reaction system. This may have occurred during mixing of the bismuth halide precursor with ODE before degassing. Although this preparative method was followed for the previous synthesis, the solvent may have gained more water over time. A second possible contamination source is through the nitrogen supply under which the syntheses took place. Both sources of impurities will be prevented in the future. 


\section{Conclusions}

This thesis explored modifications of the metal halide perovskite structure, $\mathrm{ABX}_{3}$ through heterovalent substitutions, doping, pseudohalide substitutions and nanocrystal synthesis. The ability for these modifications to take place and the effects on the resulting materials were analyzed through structural, optical, and electronic methods.

Heterovalent substitutions and doping in these materials has been largely unexplored throughout the development of these materials. ${ }^{11,27,59}$ Substitutions of $\mathrm{Pb}^{2+}$ with $\mathrm{Bi}^{3+}$ were carried out in thin film materials here to determine if a compromise between high efficiency and stability in photovoltaic devices was possible. It was discovered that a two phase material forms for those films with both $\mathrm{Bi}^{3+}$ and $\mathrm{Pb}^{2+}$ present. This has effects on the ability of the material to absorb incident light, and decreases the efficiencies of photovoltaic devices. Although the film without any $\mathrm{Pb}^{2+}$ concentration formed a single material, a wide bandgap and poor crystal morphology likely contributed to low efficiencies in the photovoltaic device. Doping of $\mathrm{MAPbI}_{3}$ thin films with $\mathrm{Bi}^{3+}$ and $\mathrm{Tl}^{+}$was carried out using similar experimental conditions as the substitutions. While the crystal structure and absorption properties of these films were not significantly affected by these modifications, the efficiencies of photovoltaic devices decreased. A larger decrease in efficiency was observed for those materials doped with $\mathrm{Bi}^{3+}$. This project will be continued with the fabrication of field-effect transistors, which will help in determining the changes in carrier concentration and mobility due to these dopants. Also, XPS measurements will be carried out to determine the final concentration of the dopants in the thin films.

Substitutions of the thiocyanate ion, $(\mathrm{SCN})^{-}$, were investigated in the $\mathrm{MAPbBr}_{3}$ structure. Previous reports of incorporation of this ion into the $\mathrm{MAPbI}_{3}$ structure were contradictory and this project set out to determine whether it is likely 
that this substitution occurs. ${ }^{65,67,68,69}$ By investigating stoichiometric substitutions over a wide range of values, it is unlikely that the $(\mathrm{SCN})^{-}$ion remains in the perovskite structure. Morphology changes, elemental analysis and optical properties of the film supported the hypothesis by Ke et al. that decomposition of $\mathrm{MA}^{+}$occurs in the presence of the $(\mathrm{SCN})^{-}$ion. ${ }^{69}$ Future work in this project includes accurate elemental analysis via XPS, in addition to synthesis of the inorganic $\mathrm{CsPb}(\mathrm{SCN})_{x} \mathrm{Br}_{3-x}$ system, which will determine whether decomposition of the reactants is the only barrier to $(\mathrm{SCN})^{-}$incorporation into the $\mathrm{ABX}_{3}$ crystal structure.

Finally, modification in the form of nanocrystal synthesis was explored in the crystal structure of $\mathrm{Cs}_{3} \mathrm{Bi}_{2} \mathrm{X}_{9}$. Here, the synthesis of $\mathrm{Cs}_{3} \mathrm{Bi}_{2} \mathrm{I}_{9}$ nanocrystals was supported through XRD, UV-Vis and TEM analysis. Subsequent reactions of the mixed halide particles, $\mathrm{Cs}_{3} \mathrm{Bi}_{2} \mathrm{Br}_{x} \mathrm{I}_{9-x}$ showed a sensitivity to oxygen contamination in the system. This unintended contamination created BiOX impurities in the reaction product. This project will continue to investigate the mixed halide compositions of these nanocrystals, with care taken to avoid any possible oxygen contamination. 


\section{References}

${ }^{1}$ D. Neaman, Semiconductor Physics And Devices: Basic Principles, 4th ed. (The McGraw Hill Companies, New York, 2012).

${ }^{2} \mathrm{M}$ Grätzel, "Dye-sensitized solid-state heterojunction solar cells", MRS bulletin 30, 23-27 (2005).

${ }^{3}$ J. A. Chang, J. H. Rhee, S. H. Im, Y. H. Lee, H.-j. Kim, S. Il Seok, M. K. Nazeeruddin, and M. Gratzel, "High-Performance Nanostructured InorganicOrganic Heterojunction Solar Cells", Nano Letters 10, 2609-2612 (2010).

${ }^{4}$ H.-S. Kim, C.-R. Lee, J.-H. Im, K.-B. Lee, T. Moehl, A. Marchioro, S.-J. Moon, R. Humphry-Baker, J.-H. Yum, J. E. Moser, M. Grätzel, and N.-G. Park, "Lead Iodide Perovskite Sensitized All-Solid-State Submicron Thin Film Mesoscopic Solar Cell with Efficiency Exceeding 9\%", Scientific Reports 2, 591 (2012).

${ }^{5}$ P. Gao, M. Grätzel, and M. K. Nazeeruddin, "Organohalide lead perovskites for photovoltaic applications", Energy \& Environmental Science 7, 2448-2463 (2014).

${ }^{6}$ A. R. West, Basic Solid State Chemistry (John Wiley \& Sons, 1999).

${ }^{7}$ V. Goldschmidt, "Die gesetze der krystallochemie", Naturwissenschaften (1926).

${ }^{8} \mathrm{D}$. Weber, " $\mathrm{CH}_{3} \mathrm{NH}_{3} \mathrm{PbX}_{3}$, ein $\mathrm{Pb}$ (II)-System mit kubischer Perowskitstruktur $\mathrm{CH}_{3} \mathrm{NH}_{3} \mathrm{PbX}_{3}$, a $\mathrm{Pb}(\mathrm{II})-$ System with Cubic Perovskite Structure", Zeitschrift für Naturforschung B 33, 1443-1445 (1978).

${ }^{9}$ C. C. Stoumpos, C. D. Malliakas, and M. G. Kanatzidis, "Semiconducting Tin and Lead Iodide Perovskites with Organic Cations: Phase Transitions, High Mobilities, and Near-Infrared Photoluminescent Properties", Inorganic Chemistry 52, 9019-9038 (2013).

${ }^{10}$ G. Kieslich, S. Sun, and A. K. Cheetham, "Solid-state principles applied to organic-inorganic perovskites: new tricks for an old dog", Chem. Sci. 5, 4712-4715 (2014).

${ }^{11}$ S. D. Stranks and H. J. Snaith, "Metal-halide perovskites for photovoltaic and light-emitting devices", Nature Nanotechnology 10, 391-402 (2015).

${ }^{12}$ C. C. Stoumpos and M. G. Kanatzidis, "Halide Perovskites: Poor Man's HighPerformance Semiconductors", Advanced Materials 28, 5778-5793 (2016).

${ }^{13}$ C. K. Møller, "Crystal Structure and Photoconductivity of Cæsium Plumbohalides", Nature 182, 1436-1436 (1958).

${ }^{14}$ D. B. Mitzi, "Templating and structural engineering in organic-inorganic perovskites", Journal of the Chemical Society, Dalton Transactions 0, 1-12 (2001). 
${ }^{15}$ A. Poglitsch and D. Weber, "Dynamic disorder in methylammoniumtrihalogenoplumbates (II) observed by millimeter-wave spectroscopy", The Journal of Chemical Physics 87, 6373-6378 (1987).

${ }^{16}$ T. Leijtens, G. E. Eperon, N. K. Noel, S. N. Habisreutinger, A. Petrozza, and H. J. Snaith, "Stability of Metal Halide Perovskite Solar Cells", Advanced Energy Materials 5, 1500963 (2015).

${ }^{17}$ A. Kojima, K. Teshima, Y. Shirai, and T. Miyasaka, "Organometal Halide Perovskites as Visible-Light Sensitizers for Photovoltaic Cells", Journal of the American Chemical Society 131, 6050-6051 (2009).

${ }^{18}$ J.-H. Im, C.-R. Lee, J.-W. Lee, S.-W. Park, and N.-G. Park, "6.5\% efficient perovskite quantum-dot-sensitized solar cell", Nanoscale 3, 4088-4093 (2011).

${ }^{19}$ S. D. Stranks, G. E. Eperon, G. Grancini, C. Menelaou, M. J. P. Alcocer, T. Leijtens, L. M. Herz, A. Petrozza, and H. J. Snaith, "Electron-Hole Diffusion Lengths Exceeding 1 Micrometer in an Organometal Trihalide Perovskite Absorber", Science 342, 341-344 (2013).

${ }^{20}$ G. Xing, N. Mathews, S. Sun, S. S. Lim, Y. M. Lam, M. Grätzel, S. Mhaisalkar, and T. C. Sum, "Long-Range Balanced Electron- and Hole-Transport Lengths in Organic-Inorganic $\mathrm{CH}_{3} \mathrm{NH}_{3} \mathrm{PbI}_{3}$ ", Science 342, 344-347 (2013).

${ }^{21}$ M. M. Lee, J. Teuscher, T. Miyasaka, T. N. Murakami, and H. J. Snaith, "Efficient Hybrid Solar Cells Based on Meso-Superstructured Organometal Halide Perovskites", Science 338, 643-647 (2012).

${ }^{22}$ L. Etgar, P. Gao, Z. Xue, Q. Peng, A. K. Chandiran, B. Liu, M. K. Nazeeruddin, and M. Grätzel, "Mesoscopic $\mathrm{CH}_{3} \mathrm{NH}_{3} \mathrm{PbI}_{3} / \mathrm{TiO}_{2}$ Heterojunction Solar Cells", Journal of the American Chemical Society 134, 17396-17399 (2012).

${ }^{23}$ J. Burschka, N. Pellet, S.-J. Moon, R. Humphry-Baker, P. Gao, M. K. Nazeeruddin, and M. Grätzel, "Sequential deposition as a route to high-performance perovskite-sensitized solar cells", Nature 499, 316-319 (2013).

${ }^{24}$ M. Liu, M. B. Johnston, and H. J. Snaith, "Efficient planar heterojunction perovskite solar cells by vapour deposition", Nature 501, 395-398 (2013).

${ }^{25}$ N. J. Jeon, J. H. Noh, W. S. Yang, Y. C. Kim, S. Ryu, J. Seo, and S. I. Seok, "Compositional engineering of perovskite materials for high-performance solar cells", Nature 517, 476-480 (2015).

${ }^{26}$ C. Yi, X. Li, J. Luo, S. M. Zakeeruddin, and M. Grätzel, "Perovskite Photovoltaics with Outstanding Performance Produced by Chemical Conversion of Bilayer Mesostructured Lead Halide/ $\mathrm{TiO}_{2}$ Films", Advanced Materials 28, 29642970 (2016). 
${ }^{27}$ P. P. Boix, S. Agarwala, T. M. Koh, N. Mathews, and S. G. Mhaisalkar, "Perovskite Solar Cells: Beyond Methylammonium Lead Iodide", The Journal of Physical Chemistry Letters 6, 898-907 (2015).

${ }^{28}$ J. H. Noh, S. H. Im, J. H. Heo, T. N. Mandal, and S. I. Seok, "Chemical Management for Colorful, Efficient, and Stable Inorganic-Organic Hybrid Nanostructured Solar Cells", Nano Letters 13, 1764-1769 (2013).

${ }^{29}$ G. E. Eperon, S. D. Stranks, C. Menelaou, M. B. Johnston, L. M. Herz, and H. J. Snaith, "Formamidinium lead trihalide: a broadly tunable perovskite for efficient planar heterojunction solar cells", Energy Environ. Sci. 7, 982-988 (2014).

${ }^{30}$ I. Borriello, G. Cantele, and D. Ninno, "Ab initio investigation of hybrid organicinorganic perovskites based on tin halides", Physical Review B 77, 235214 (2008).

${ }^{31}$ I. E. Castelli, J. M. García-Lastra, K. S. Thygesen, and K. W. Jacobsen, "Bandgap calculations and trends of organometal halide perovskites", APL Materials 2, 081514 (2014).

${ }^{32}$ F. Hao, C. C. Stoumpos, D. H. Cao, R. P. H. Chang, and M. G. Kanatzidis, "Lead-free solid-state organic-inorganic halide perovskite solar cells", Nature Photonics 8, 489-494 (2014).

${ }^{33}$ Y. Ogomi, A. Morita, S. Tsukamoto, T. Saitho, N. Fujikawa, Q. Shen, T. Toyoda, K. Yoshino, S. S. Pandey, T. Ma, and S. Hayase, " $\mathrm{CH}_{3} \mathrm{NH}_{3} \mathrm{Sn}_{x} \mathrm{~Pb}_{(1-x)} \mathrm{I}_{3}$ Perovskite Solar Cells Covering up to 1060 nm", The Journal of Physical Chemistry Letters 5, 1004-1011 (2014).

${ }^{34}$ M. H. Kumar, S. Dharani, W. L. Leong, P. P. Boix, R. R. Prabhakar, T. Baikie, C. Shi, H. Ding, R. Ramesh, M. Asta, M. Graetzel, S. G. Mhaisalkar, and N. Mathews, "Lead-Free Halide Perovskite Solar Cells with High Photocurrents Realized Through Vacancy Modulation", Advanced Materials 26, 7122-7127 (2014).

${ }^{35}$ X. Qiu, B. Cao, S. Yuan, X. Chen, Z. Qiu, Y. Jiang, Q. Ye, H. Wang, H. Zeng, J. Liu, and M. G. Kanatzidis, "From unstable CsSnI3 to air-stable $\mathrm{Cs}_{2} \mathrm{SnI}_{6}$ : A lead-free perovskite solar cell light absorber with bandgap of $1.48 \mathrm{eV}$ and high absorption coefficient", Solar Energy Materials and Solar Cells 159, 227-234 (2017).

${ }^{36}$ A. Babayigit, D. Duy Thanh, A. Ethirajan, J. Manca, M. Muller, H.-G. Boyen, and B. Conings, "Assessing the toxicity of $\mathrm{Pb}$ - and Sn-based perovskite solar cells in model organism Danio rerio", Scientific Reports 6, 18721 (2016).

${ }^{37}$ Y. Yin and A. P. Alivisatos, "Colloidal nanocrystal synthesis and the organic-inorganic interface", Nature 437, 664-670 (2005).

${ }^{38}$ L. Brus, "Electronic wave functions in semiconductor clusters: experiment and theory", The Journal of Physical Chemistry 90, 2555-2560 (1986). 
${ }^{39}$ Y. Wang and N. Herron, "Nanometer-sized semiconductor clusters: materials synthesis, quantum size effects, and photophysical properties", The Journal of Physical Chemistry 95, 525-532 (1991).

${ }^{40}$ C. B. Murray, D. J. Norris, and M. G. Bawendi, "Synthesis and characterization of nearly monodisperse $\mathrm{CdE}(\mathrm{E}=$ sulfur, selenium, tellurium) semiconductor nanocrystallites", Journal of the American Chemical Society 115, 8706-8715 (1993).

${ }^{41}$ A. H. Ip, S. M. Thon, S. Hoogland, O. Voznyy, D. Zhitomirsky, R. Debnath, L. Levina, L. R. Rollny, G. H. Carey, A. Fischer, K. W. Kemp, I. J. Kramer, Z. Ning, A. J. Labelle, K. W. Chou, A. Amassian, and E. H. Sargent, "Hybrid passivated colloidal quantum dot solids", Nature Nanotechnology 7, 577-582 (2012).

${ }^{42}$ L. Protesescu, S. Yakunin, M. I. Bodnarchuk, F. Krieg, R. Caputo, C. H. Hendon, R. X. Yang, A. Walsh, and M. V. Kovalenko, "Nanocrystals of Cesium Lead Halide Perovskites $\left(\mathrm{CsPbX}_{3}, \mathrm{X}=\mathrm{Cl}, \mathrm{Br}\right.$, and I): Novel Optoelectronic Materials Showing Bright Emission with Wide Color Gamut", Nano Letters 15, 3692-3696 (2015).

${ }^{43}$ D. Zhang, S. W. Eaton, Y. Yu, L. Dou, and P. Yang, "Solution-Phase Synthesis of Cesium Lead Halide Perovskite Nanowires", Journal of the American Chemical Society 137, 9230-9233 (2015).

${ }^{44}$ G. Nedelcu, L. Protesescu, S. Yakunin, M. I. Bodnarchuk, M. J. Grotevent, and M. V. Kovalenko, "Fast Anion-Exchange in Highly Luminescent Nanocrystals of Cesium Lead Halide Perovskites $\left(\mathrm{CsPbX}_{3}, \mathrm{X}=\mathrm{Cl}, \mathrm{Br}, \mathrm{I}\right)$ ", Nano Letters 15, 5635-5640 (2015).

${ }^{45}$ J. A. Sichert, Y. Tong, N. Mutz, M. Vollmer, S. Fischer, K. Z. Milowska, R. García Cortadella, B. Nickel, C. Cardenas-Daw, J. K. Stolarczyk, A. S. Urban, and J. Feldmann, "Quantum Size Effect in Organometal Halide Perovskite Nanoplatelets", Nano Letters 15, 6521-6527 (2015).

${ }^{46}$ B. D. Viezbicke, S. Patel, B. E. Davis, and D. P. Birnie, "Evaluation of the Tauc method for optical absorption edge determination: $\mathrm{ZnO}$ thin films as a model system", physica status solidi (b) 252, 1700-1710 (2015).

${ }^{47}$ R. F. Egerton, Physical Principles of Electron Microscopy (Springer US, Boston, MA, 2005).

${ }^{48}$ B.-W. Park, B. Philippe, X. Zhang, H. Rensmo, G. Boschloo, and E. M. J. Johansson, "Bismuth Based Hybrid Perovskites $\mathrm{A}_{3} \mathrm{Bi}_{2} \mathrm{I}_{9}$ (A: Methylammonium or Cesium) for Solar Cell Application", Advanced Materials 27, 6806-6813 (2015). 
${ }^{49}$ R. L. Z. Hoye, R. E. Brandt, A. Osherov, V. Stevanović, S. D. Stranks, M. W. B. Wilson, H. Kim, A. J. Akey, J. D. Perkins, R. C. Kurchin, J. R. Poindexter, E. N. Wang, M. G. Bawendi, V. Bulović, and T. Buonassisi, "Methylammonium Bismuth Iodide as a Lead-Free, Stable Hybrid Organic-Inorganic Solar Absorber", Chemistry - A European Journal 22, 2605-2610 (2016).

${ }^{50}$ S. Öz, J.-C. Hebig, E. Jung, T. Singh, A. Lepcha, S. Olthof, F. Jan, Y. Gao, R. German, P. H. van Loosdrecht, K. Meerholz, T. Kirchartz, and S. Mathur, "Zero-dimensional $\left(\mathrm{CH}_{3} \mathrm{NH}_{3}\right)_{3} \mathrm{Bi}_{2} \mathrm{I}_{9}$ perovskite for optoelectronic applications", Solar Energy Materials and Solar Cells 158, 195-201 (2016).

${ }^{51}$ T. Singh, A. Kulkarni, M. Ikegami, and T. Miyasaka, "Effect of Electron Transporting Layer on Bismuth-Based Lead-Free Perovskite $\left(\mathrm{CH}_{3} \mathrm{NH}_{3}\right)_{3} \mathrm{Bi}_{2} \mathrm{I}_{9}$ for Photovoltaic Applications", ACS Applied Materials \& Interfaces 8, 14542-14547 (2016).

${ }^{52}$ X. Zhang, G. Wu, Z. Gu, B. Guo, W. Liu, S. Yang, T. Ye, C. Chen, W. Tu, and H. Chen, "Active-layer evolution and efficiency improvement of $\left(\mathrm{CH}_{3} \mathrm{NH}_{3}\right)_{3} \mathrm{Bi}_{2} \mathrm{I}_{9}$ based solar cell on $\mathrm{TiO}_{2}$-deposited ITO substrate", Nano Research 9, 2921-2930 (2016).

${ }^{53} \mathrm{O}$ Lindqvist, "The Crystal Structure of Caesium Bismuth Iodide, $\mathrm{Cs}_{3} \mathrm{Bi}_{2} \mathrm{I}_{9}$ ", Acta Chemica Scandinavica 22, 2943-2952 (1968).

${ }^{54}$ R. Jakubas, J. Zaleski, and L. Sobczyk, "Phase transitions in $\left(\mathrm{CH}_{3} \mathrm{NH}_{3}\right)_{3} \mathrm{Bi}_{2} \mathrm{I}_{9}$ (MAIB)", Ferroelectrics 108, 109-114 (1990).

${ }^{55}$ J. Kim, S.-H. Lee, J. H. Lee, and K.-H. Hong, "The Role of Intrinsic Defects in Methylammonium Lead Iodide Perovskite", The Journal of Physical Chemistry Letters 5, 1312-1317 (2014).

${ }^{56}$ T. Baikie, Y. Fang, J. M. Kadro, M. Schreyer, F. Wei, S. G. Mhaisalkar, M. Graetzel, and T. J. White, "Synthesis and crystal chemistry of the hybrid perovskite $\left(\mathrm{CH}_{3} \mathrm{NH}_{3}\right) \mathrm{PbI}_{3}$ for solid-state sensitised solar cell applications", Journal of Materials Chemistry A 1, 5628-5641 (2013).

${ }^{57}$ M. Pazoki, M. B. Johansson, H. Zhu, P. Broqvist, T. Edvinsson, G. Boschloo, and E. M. J. Johansson, "Bismuth Iodide Perovskite Materials for Solar Cell Applications: Electronic Structure, Optical Transitions, and Directional Charge Transport", The Journal of Physical Chemistry C 120, 29039-29046 (2016).

${ }^{58}$ A. J. Lehner, D. H. Fabini, H. A. Evans, C.-A. Hébert, S. R. Smock, J. Hu, H. Wang, J. W. Zwanziger, M. L. Chabinyc, and R. Seshadri, "Crystal and Electronic Structures of Complex Bismuth Iodides $\mathrm{A}_{3} \mathrm{Bi}_{2} \mathrm{I}_{9}(\mathrm{~A}=\mathrm{K}, \mathrm{Rb}, \mathrm{Cs}$ ) Related to Perovskite: Aiding the Rational Design of Photovoltaics", Chemistry of Materials 27, 7137-7148 (2015). 
${ }^{59}$ A. L. Abdelhady, M. I. Saidaminov, B. Murali, V. Adinolfi, O. Voznyy, K. Katsiev, E. Alarousu, R. Comin, I. Dursun, L. Sinatra, E. H. Sargent, O. F. Mohammed, and O. M. Bakr, "Heterovalent Dopant Incorporation for Bandgap and Type Engineering of Perovskite Crystals", The Journal of Physical Chemistry Letters 7, 295-301 (2016).

${ }^{60} \mathrm{P}$. Van Mieghem, "Theory of band tails in heavily doped semiconductors", Reviews of Modern Physics 64, 755-793 (1992).

${ }^{61}$ R. D. Shannon, "Revised Effective Ionic Radii and Systematic Studies of Interatomie Distances in Halides and Chaleogenides", Acta Cryst 32, 751-767 (1976).

${ }^{62}$ C. Li, X. Lu, W. Ding, L. Feng, Y. Gao, and Z. Guo, "Formability of $\mathrm{ABX}_{3}(\mathrm{X}=$ F, Cl, Br, I) Halide Perovskites", Acta Crystallographica Section B: Structural Science 64, 702-707 (2008).

${ }^{63}$ X. Y. Chin, D. Cortecchia, J. Yin, A. Bruno, and C. Soci, "Lead iodide perovskite light-emitting field-effect transistor", Nature Communications 6, 7383 (2015).

${ }^{64}$ Z. Xiao, Y. Yuan, Y. Shao, Q. Wang, Q. Dong, C. Bi, P. Sharma, A. Gruverman, and J. Huang, "Giant switchable photovoltaic effect in organometal trihalide perovskite devices", Nature materials 14, 193-198 (2015).

${ }^{65}$ Q. Jiang, D. Rebollar, J. Gong, E. L. Piacentino, C. Zheng, and T. Xu, "PseudohalideInduced Moisture Tolerance in Perovskite $\mathrm{CH}_{3} \mathrm{NH}_{3} \mathrm{~Pb}(\mathrm{SCN})_{2} \mathrm{I}$ Thin Films", Angewandte Chemie 127, 7727-7730 (2015).

${ }^{66}$ Y. Chen, B. Li, W. Huang, D. Gao, and Z. Liang, "Efficient and reproducible $\mathrm{CH}_{3} \mathrm{NH}_{3} \mathrm{PbI}_{3-x}(\mathrm{SCN}) \mathrm{x}$ perovskite based planar solar cells", Chem. Commun. 51, 11997-11999 (2015).

${ }^{67}$ M. Daub and H. Hillebrecht, "Synthesis, Single-Crystal Structure and Characterization of $\left(\mathrm{CH}_{3} \mathrm{NH}_{3}\right)_{2} \mathrm{~Pb}(\mathrm{SCN})_{2} \mathrm{I}_{2}$ ", Angewandte Chemie International Edition 54, 11016-11017 (2015).

${ }^{68}$ Z. Xiao, W. Meng, B. Saparov, H.-S. Duan, C. Wang, C. Feng, W. Liao, W. Ke, D. Zhao, J. Wang, D. B. Mitzi, and Y. Yan, "Photovoltaic Properties of TwoDimensional $\left(\mathrm{CH}_{3} \mathrm{NH}_{3}\right)_{2} \mathrm{~Pb}(\mathrm{SCN})_{2} \mathrm{I}_{2}$ Perovskite: A Combined Experimental and Density Functional Theory Study", The Journal of Physical Chemistry Letters 7, 1213-1218 (2016).

${ }^{69}$ W. Ke, C. Xiao, C. Wang, B. Saparov, H.-S. Duan, D. Zhao, Z. Xiao, P. Schulz, S. P. Harvey, W. Liao, W. Meng, Y. Yu, A. J. Cimaroli, C.-S. Jiang, K. Zhu, M. Al-Jassim, G. Fang, D. B. Mitzi, and Y. Yan, "Employing Lead Thiocyanate Additive to Reduce the Hysteresis and Boost the Fill Factor of Planar Perovskite Solar Cells", Advanced Materials 28, 5214-5221 (2016). 
${ }^{70}$ T. C. Jellicoe, J. M. Richter, H. F. J. Glass, M. Tabachnyk, R. Brady, S. E. Dutton, A. Rao, R. H. Friend, D. Credgington, N. C. Greenham, and M. L. Böhm, "Synthesis and Optical Properties of Lead-Free Cesium Tin Halide Perovskite Nanocrystals", Journal of the American Chemical Society 138, 29412944 (2016).

${ }^{71}$ M. Leng, Z. Chen, Y. Yang, Z. Li, K. Zeng, K. Li, G. Niu, Y. He, Q. Zhou, and J. Tang, "Lead-Free, Blue Emitting Bismuth Halide Perovskite Quantum Dots", Angewandte Chemie International Edition 55, 15012-15016 (2016).

72Z.-Y. Zhao and W.-W. Dai, "Structural, Electronic, and Optical Properties of Eu-Doped BiOX (X = F, Cl, Br, I): A DFT+U Study", Inorganic Chemistry 53, 13001-13011 (2014). 